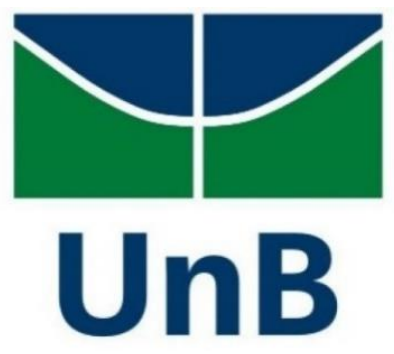

UNIVERSIDADE DE BRASÍLIA

FACULDADE DE CIÊNCIAS DA SAÚDE

PROGRAMA DE PÓS-GRADUAÇÃO EM SAÚDE COLETIVA

MESTRADO PROFISSIONAL EM SAÚDE COLETIVA

\title{
GESTÃO DA ASSISTÊNCIA FARMACÊUTICA EM REGIÕES DE SAÚDE DO CEARÁ: um recorte do Projeto QualiSUS-Rede
}

Mestrando: Wendell Rodrigues Oliveira da Silva Orientadora: Prof. Dra. Noemia Urruth Leão Tavares 
UNIVERSIDADE DE BRASILIA

FACULDADE DE CIÊNCIAS DA SAÚDE

PROGRAMA DE PÓS-GRADUAÇÃO EM SAÚDE COLETIVA

DISSERTAÇÃO DE MESTRADO

GESTÃO DA ASSISTÊNCIA FARMACÊUTICA EM REGIÕES DE SAÚDE DO

CEARÁ: um recorte do Projeto QualiSUS-Rede

Mestrando: Wendell Rodrigues Oliveira da Silva

Dissertação apresentada como requisito parcial para a obtenção do título de mestre em Saúde Coletiva pelo Programa de Pós-Graduação em Saúde Coletiva, Universidade de Brasília.

Orientador: Prof. Dra. Noemia Urruth Leão Tavares

Brasília, Brasil. 
Mestrando: Wendell Rodrigues Oliveira da Silva

\section{GESTÃO DA ASSISTÊNCIA FARMACÊUTICA EM REGIÕES DE SAÚDE DO CEARÁ: um recorte do Projeto QualiSUS-Rede}

Dissertação apresentada como requisito parcial para a obtenção do título de mestre em Saúde Coletiva pelo Programa de Pós-Graduação em Saúde Coletiva, Universidade de Brasília.

Aprovado em 22/02/2017

\section{BANCA EXAMINADORA}

Prof. Dra. Noemia Urruth Leão Tavares [Presidente]

Universidade de Brasília - UnB

Prof. Dra. Dayde Lane Mendonça [Membro Externo]

Universidade de Brasília - UnB

Prof. Tania Cristina Santa Bárbara Rehem [Membro Interno]

Universidade de Brasília - UnB

Prof. Dra. Maria Fátima de Sousa [Suplente]

Universidade de Brasília - UnB 
Dedico esse trabalho a minha família, Luciana Soares (esposa), Ana Isabel e Luiz Neto (filhos) e a meus pais (Sr. Freire e D. Ivonilde) que sempre torceram por mim e sempre mostraram como é bom e importante o estudo, e dedico ainda a todos, que assim como eu, são apaixonados pela Assistência Farmacêutica. 
AGRADECIMENTOS

Agradeço em primeiro lugar a DEUS pela imensa sabedoria e por ter me proporcionado cursar esse mestrado;

A Luciana Soares (esposa) pela força e paciência nas horas que tive que dedicar às aulas, trabalhos e a esse projeto;

A Ana Isabel e Luiz Neto (filhos), maior fonte de inspiração e motivação;

A Sr. Freire e a D. Ivonilde por sempre mostrarem a importância do estudo.

A Noemia Tavares (Orientadora) e a Karen Costa por terem acreditado em mim e aceitado me orientarem nesse trabalho. 


\section{RESUMO}

Esse trabalho tem por objetivo analisar a gestão da Assistência Farmacêutica em regiões de saúde da Região Semiárido Cariri/CE quanto as suas estruturas formais, os serviços farmacêuticos técnicos gerenciais ofertados e/ou praticados e os recursos humanos envolvidos, por meio de informações obtidas com o Projeto QualiSUS-Rede. Foram entrevistados os responsáveis pela Assistência Farmacêutica em 19 municípios. Entre os resultados destaca-se que a Assistência Farmacêutica faz parte do organograma da Secretaria Municipal de Saúde em 84,2\% dos municípios. Em relação ao financiamento, foi referido por 68,4\% dos responsáveis a insuficiência do recurso do Componente Básico da Assistência Farmacêutica para aquisição de medicamentos padronizados, entretanto a grande parte referiu que não foi aplicado o valor mínimo tanto pelo município $(21,1 \%)$ como pelo Estado $(31,6 \%)$. Nenhum dos municípios realizam monitoramento e avaliação da Assistência Farmacêutica por meio de indicadores. Esperamos, com os resultados observados nesse estudo, contribuir para a melhoria da gestão da Assistência Farmacêutica, visando a promoção do acesso aos medicamentos a população das regiões de saúde.

Palavras-chave: Sistemas de Saúde; Regionalização; Assistência Farmacêutica 


\begin{abstract}
This work aims at analysing the management of the Pharmaceutical Service in the health regions of the Semiarid Cariri/CE Region, in relation to its formal structures, pharmaceutical technical management services offered and/or practised, and the human resources involved, with information obtained through the project QualiSUSRede [QualiSUS-Network]. People from 19 municipalities who are responsible for the PA were interviewed. Some of the most remarkable results show that Pharmaceutical Assistance is part of the Municipal Secretariat of Health organization chart in $84.2 \%$ of the municipalities. Regarding funding, $68.4 \%$ of those responsible for the PA stated the Basic Component of Pharmaceutical Assistance (BCPA) had insufficient resources to acquire standardized medicines, however, most of them said the minimum price was not applied neither by the municipality $(21.1 \%)$ nor by the State $(31.6 \%)$. None of the municipalities supervise or evaluate the Pharmaceutical Assistance by means of indicators. Through this research we hope to contribute to the improvement of the Pharmaceutical Assistance management, and aim at promoting the access to medicines by the population from the health regions.
\end{abstract}

Keywords: Health Systems; Regionalization; Pharmaceutical Service 


\section{LISTA DE ABREVIATURAS E SIGLAS}

\begin{tabular}{|c|c|}
\hline ABS & Atenção Básica à Saúde \\
\hline $\mathrm{AF}$ & Assistência Farmacêutica \\
\hline ANVISA & Agência Nacional de Vigilância Sanitária \\
\hline CAF & Central de Abastecimento Farmacêutico \\
\hline CAPS & Centro de Atenção Psicossocial \\
\hline CASAI & Casas de Saúde do Índio \\
\hline CBAF & Componente Básico da Assistência Farmacêutica \\
\hline CFM & Conselho Federal de Medicina \\
\hline CGAFB & Coordenação Geral de Assistência Farmacêutica Básica \\
\hline CIB & Comissão Intergestora Bipartite \\
\hline CNES & Cadastro Nacional de Estabelecimentos de Saúde \\
\hline COAP & Contratos Organizativos de Ação Pública \\
\hline CONASEMS & Conselho Nacional de Secretarias Municipais de Saúde \\
\hline CONASS & Conselho Nacional de Secretários de Saúde \\
\hline CONEP & Conselho Nacional de Ética em Pesquisa \\
\hline DAF & Departamento de Assistência Farmacêutica e Insumos Estratégicos \\
\hline DATASUS & Departamento de Informática do Sistema Único de Saúde \\
\hline DEMAS & Departamento de Monitoramento e Avaliação do SUS \\
\hline DSEI & Distritos Sanitários Especiais Indígenas \\
\hline ECT & Empresa de Correios e Telégrafos \\
\hline FTN & Formulário Terapêutico Nacional \\
\hline HÓRUS & Sistema Nacional de Gestão da Assistência Farmacêutica \\
\hline MS & Ministério da Saúde \\
\hline PMAQ & $\begin{array}{l}\text { Programa Nacional de Melhoria do Acesso e da Qualidade da Atenção } \\
\text { Básica }\end{array}$ \\
\hline PNM & Política Nacional de Medicamentos \\
\hline QUALIFAR-SUS & Programa Nacional de Qualificação da Assistência Farmacêutica \\
\hline RAS & Redes de Atenção à Saúde \\
\hline RENAME & Relação Nacional de Medicamentos Essenciais \\
\hline RENASES & Relação Nacional de Ações e Serviços de Saúde \\
\hline SAGE & Sala de Apoio à Gestão Estratégica \\
\hline SASISUS & Subsistema de Atenção à Saúde Indígena \\
\hline SCTIE & Secretaria de Ciência, Tecnologia e Insumos Estratégicos \\
\hline SESAI & Secretaria Especial de Saúde Indígena \\
\hline SGEP & Secretaria de Gestão Estratégica e Participativa \\
\hline STF & Superior Tribunal Federal \\
\hline SUS & Sistema Único de Saúde \\
\hline UGP & Unidade de Gestão de Projetos - QualiSUS-Rede \\
\hline
\end{tabular}




\section{LISTA DE QUADROS}

QUADRO 1 Região Semiárido Cariri/CE

QUADRO 2 Quadro dos indicadores de acordo com as categorias de análise. QualiSUS Rede, 2015

\section{LISTA DE TABELAS}

TABELA 1 Indicadores referentes a aquisição de medicamentos e financiamento da Assistência Farmacêutica, segundo responsável pela Assistência Farmacêutica municipal. QualisSUS Rede, 2015 (n=19)

TABELA 2 Indicadores referentes ao planejamento, segundo responsável pela Assistência Farmacêutica municipal. QualisSUS Rede, 2015

TABELA 3 Indicadores referentes a estruturais formais e sistema de informação da Assistência Farmacêutica, segundo responsável pela Assistência Farmacêutica municipal. QualisSUS Rede, 2015 (n=19). 


\section{SUMÁRIO}

1. APRESENTAÇÃO 11

2. INTRODUÇÃO 12

3. OBJETIVOS 13

3.1. Objetivo Geral 13

3.2. Objetivos Específicos 13

4. REFERENCIAL TEÓRICO 14

4.1. Assistência Farmacêutica no Sistema Único de Saúde 14

4.2. Aquisição e financiamento da Assistência Farmacêutica 16

4.3. Planejamento e Gestão da Assistência Farmacêutica no SUS 18

4.4. Sistemas de informação na Assistência Farmacêutica 19

4.5. As Redes de Atenção à Saúde e a Assistência Farmacêutica 21

4.6. O QualiSUS-Rede 23

5. MÉTODOS 27

6. RESULTADOS E DISCUSSÕES 31

6.1 ARTIGO 31

7. CONCLUSÕES 46

8. CONSIDERAÇÕES FINAIS 47

REFERÊNCIAS BIBLIOGRÁFICAS 48

$\begin{array}{ll}\text { ANEXOS } & 51\end{array}$ 


\section{APRESENTAÇÃO}

Este trabalho consiste na dissertação de mestrado intitulada "GESTÃO DA ASSISTÊNCIA FARMACÊUTICA EM REGIÕES DE SAÚDE DO CEARÁ: um recorte do Projeto QualiSUS-Rede", apresentada ao Programa de Pós-Graduação em Saúde Coletiva da Universidade de Brasília, em 22 de fevereiro de 2017.

A motivação pela escolha do tema vem da experiência do pesquisador, farmacêuticobioquímico, pós-graduado em Gestão da Assistência Farmacêutica, que atuou na sua trajetória profissional na gestão da Assistência Farmacêutica em municípios do Ceará e atualmente como consultor técnico na Coordenação Geral da Assistência Farmacêutica Básica no Departamento de Assistência Farmacêutica do Ministério da Saúde (DAF/SCTIE/MS).

O presente trabalho é apresentado em três partes, na ordem que segue:

1. Introdução, Objetivos, Referencial Teórico, Método

2. Artigo

3. Considerações Finais

Documentos de apoio estão apresentados nos anexos. 


\section{INTRODUÇÃO}

O Sistema Único de Saúde (SUS), instituído por meio da Lei Orgânica da Saúde $(1990)^{(1)}$, tem como objetivo assegurar o acesso da população aos serviços de promoção, proteção e recuperação da saúde deflagrou o processo de elaboração de um conjunto de políticas públicas relativas à saúde. Inserem-se nesse conjunto a Política Nacional de Medicamentos, de 1998, e a Política Nacional de Assistência Farmacêutica, de 2004, promulgadas com o propósito de garantir o acesso a medicamentos aliado à promoção de seu uso racional e construir um arcabouço legal para sustentar o processo de descentralização da gestão das ações da Assistência Farmacêutica no SUS ${ }^{(2)}$

A Assistência Farmacêutica vem sendo implementada de forma articulada entre os gestores do SUS, sendo a responsabilidade pelo seu financiamento das três esferas de gestão do SUS (federal, estadual, municipal), e a sua execução e responsabilidades pactuadas nas instâncias intergestoras com o objetivo de organizar as atividades relacionadas à gestão dos medicamentos, visando garantir o acesso da população ${ }^{(3)}$.

Se por um lado, temos um avanço e consolidação legal da Assistência Farmacêutica estruturada pelas respectivas leis e portarias, que norteiam e contribuem para uma melhor organização da AF nos municípios, observa-se ainda problemas referentes a gestão dos recursos e/ou de serviços farmacêuticos, seja por má utilização dos recursos financeiros, ausência de planejamento e programação para a aquisição de medicamentos; e o armazenamento em condições inapropriadas ocasionando perdas de medicamentos ${ }^{(2,4)}$.

Os desafios atuais para a gestão da assistência farmacêutica de ultrapassar a visão procedimental e minimalista do ciclo gerencial, passando a ter o usuário como centro das atividades é reforçada pela demanda crescente por medicamentos que envolve elevado aporte de recursos financeiros para garantir à população, o acesso regular aos medicamentos e ao mesmo tempo a necessidade de otimização da terapêutica ofertada com a promoção do uso racional dos medicamentos. Portanto, a Assistência Farmacêutica, exerce um importante papel no setor produtivo, na inovação e no desenvolvimento tecnológico e, de outro lado, é essencial na produção de serviços, propiciando integralidade e resolutividade às ações de saúde $^{(5)}$.

Neste contexto, esse trabalho tem por objetivo caracterizar a gestão da Assistência Farmacêutica quanto as suas estruturas formais, os serviços farmacêuticos técnicos gerenciais ofertados e/ou praticados em municípios das regiões de saúde da Região do Semiárido do Cariri/CE. 


\section{OBJETIVOS}

\subsection{Geral}

Analisar a caracterização da gestão da Assistência Farmacêutica em regiões de saúde da Região Semiárido Cariri/CE.

\subsection{Específicos}

$\checkmark$ Caracterizar a organização da Assistência Farmacêutica quanto as estruturas formais e o Responsável pela Assistência Farmacêutica envolvidos nos municípios das regiões de saúde;

$\checkmark$ Descrever os indicadores relativos a aquisição e financiamento de medicamentos do Componente Básico da Assistência Farmacêutica utilizados;

$\checkmark$ Verificar a participação dos responsáveis pela assistência farmacêutica no planejamento municipal;

$\checkmark$ Apontar as lacunas identificadas na gestão da assistência farmacêutica nas regiões com vistas a qualificação dos serviços. 


\section{REFERENCIAL TEÓRICO}

\subsection{Assistência Farmacêutica no Sistema Único de Saúde}

Decorridos mais de vinte e cinco anos desde o advento do SUS, pode-se verificar seu impacto positivo na saúde da população. Esses avanços podem ser percebidos em relação à ampliação da cobertura, à melhoria da assistência e aos seus mecanismos de gestão.

A situação de saúde da população brasileira e o atual estágio de desenvolvimento do Sistema Único de Saúde (SUS) impõem aos gestores e profissionais de saúde o desafio da garantia da integralidade do cuidado.

O avanço da ciência e a inovação tecnológica no desenvolvimento de medicamentos têm contribuído de forma efetiva para o controle das doenças, propiciando aumento na expectativa de vida de indivíduos e grupos populacionais, fato que por sua vez demanda novos medicamentos.

O Sistema Único de Saúde (SUS), estabelecido pela Constituição Federal de 1988, tem como princípios doutrinários a universalidade, equidade e integralidade, e está organizado sob as diretrizes organizativas da descentralização, regionalização-hierarquização, resolubilidade, participação da comunidade e complementaridade do setor privado e estabelece, no artigo $6^{\circ}$, a garantia da assistência terapêutica, integral, na qual se insere a Assistência Farmacêutica $(\mathrm{AF})$.

A AF pode ser entendida como um conjunto de atividades sistêmicas articuladas como um ciclo, que se sucedem e só se completam na medida em que a atividade anterior for adequadamente realizada. Neste ciclo, incluem-se as seguintes atividades: seleção, programação, aquisição, armazenamento, distribuição e utilização (que abrange a prescrição, a dispensação e o uso) $)^{(6)}$.

A AF se constitui em importante componente integrante do SUS, sendo fundamental para efetiva implementação das ações de promoção, prevenção e melhoria das condições da assistência à saúde da população.

A ampliação do acesso da população ao sistema de saúde público, principalmente por meio da Atenção Básica à Saúde (ABS), exigiu mudanças na organização da AF dentro do SUS, de maneira a aumentar a cobertura da distribuição gratuita de medicamentos, ao mesmo passo de minimizar custos e construir um arcabouço legal para sustentar o processo de descentralização da gestão das ações da $\mathrm{AF}^{(3)}$. 
A disponibilidade de medicamentos é vista como um elemento primordial em um sistema de saúde de qualidade, representando um indicativo de credibilidade dos serviços e ações em saúde ${ }^{(7)}$.

O acesso aos medicamentos, entendido como bem de saúde, é garantido constitucionalmente em nosso país. A Política Nacional de Medicamentos (PNM) brasileira em vigor foi institucionalizada através da Portaria $\mathrm{n}^{\circ} 3.916$ de 1998 e tem como finalidades principais:

- A garantia da necessária segurança, da eficácia e da qualidade dos medicamentos;

- A promoção do uso racional dos medicamentos;

- $\quad$ acesso da população aos medicamentos considerados essenciais ${ }^{(8)}$.

Para alguns autores, o acesso implica a garantia de ingresso do indivíduo no sistema de saúde e/ou o uso de bens e serviços considerados socialmente importantes, sem obstáculos físicos, financeiros ou de outra natureza.

Desde a implantação da PNM, foi estabelecida a reorientação da AF, direcionada para o seu intensivo processo de descentralização. Esta nova lógica estabeleceu a responsabilidade dos três níveis de gestão, tanto no que se refere ao financiamento, como ao estabelecimento de políticas em prol da promoção do acesso e uso racional de medicamentos ${ }^{(8)}$.

Em 2003, Marin et al afirma que o medicamento passa a ser um:

\begin{abstract}
"objeto desvirtuado no Sistema de Saúde, inviabilizando o desenvolvimento de um enfoque que priorize o cuidado com a terapêutica medicamentosa, envolvendo nessa concepção a formação dos profissionais, o processo de educação continuada, a orientação à população e o acompanhamento do uso adequado e racional dos medicamentos ${ }^{\prime \prime(9)}$.
\end{abstract}

Há um interesse nacional em aprimorar o acesso aos medicamentos, portanto, a PNM vem se organizando através da publicação de Leis, Portarias, Decretos, Diretrizes e Programas, para regulamentar aspectos importantes da gestão da Assistência Farmacêutica, entre eles, as formas de financiamento e os mecanismos de distribuição de medicamentos.

$\mathrm{O}$ aprimoramento necessário da Política Nacional da AF visava à superação do entendimento da AF, com foco no medicamento para o cuidado com as pessoas, e está presente na Política Nacional de Assistência Farmacêutica, formulada em 2004:

“...conjunto de ações voltadas à promoção, proteção e recuperação da saúde, tanto individual como coletivo, tendo o medicamento como insumo essencial e visando o acesso e ao seu uso racional. Este conjunto envolve a pesquisa, o desenvolvimento e a produção de medicamentos e insumos, bem como a sua seleção, programação, aquisição, distribuição, dispensação, garantia da qualidade dos produtos e serviços, acompanhamento e avaliação de sua utilização, na perspectiva da obtenção de resultados concretos e da melhoria da qualidade de vida da população." (Brasil, 2004, Artigo $1^{\circ}$, III). 
“...Compreendida também como política pública norteadora para a formulação de políticas setoriais, entre as quais se destacam as políticas de medicamentos, de ciência e tecnologia, de desenvolvimento industrial e de formação de recursos humanos, dentre outras..." (10).

\subsection{Aquisição e financiamento da Assistência Farmacêutica}

A demanda crescente por medicamentos envolve elevado aporte de recursos financeiros, cujo gerenciamento efetivo pode propiciar, à população, o acesso regular aos medicamentos. Portanto, a AF exerce um importante papel no setor produtivo, na inovação e no desenvolvimento tecnológico e, de outro lado, é essencial na produção de serviços, propiciando integralidade e resolutividade às ações de saúde. A complexidade dos processos de AF envolve a articulação e sincronismo entre os serviços e a ação cooperativa dos profissionais de saúde.

O financiamento execução da AF Básica é regulamentado atualmente pela portaria Portaria $\mathrm{N}^{\mathrm{o}} 1.555^{(11)}$, de 30 de julho de 2013, que dispõe sobre as normas de financiamento e de execução do Componente Básico da Assistência Farmacêutica (CBAF) no âmbito do Sistema Único de Saúde, recurso destinado à aquisição de medicamentos e insumos, incluindo-se aqueles relacionados a agravos e programas de saúde específicos, no âmbito da Atenção Básica à Saúde.

Segundo essa portaria, o financiamento do CBAF é de responsabilidade da União, dos Estados, do Distrito Federal e dos Municípios, conforme normas estabelecidas nesta Portaria, com aplicação, no mínimo, dos seguintes valores de seus orçamentos próprios: União: R \$ 5,10 (cinco reais e dez centavos) por habitante/ano, para financiar a aquisição dos medicamentos e insumos do Componente Básico da Assistência Farmacêutica constantes dos Anexos I e IV da Relação Nacional de Medicamentos Essenciais (RENAME) vigente no SUS; estados: R $\$ 2,36$ (dois reais e trinta e seis centavos) por habitante/ano, para financiar a aquisição dos medicamentos e insumos constantes dos Anexos I e IV da RENAME vigente no SUS, incluindo os insumos para os usuários insulinodependentes estabelecidos na Portaria $\mathrm{n}^{\circ}$ 2.583/GM/MS, de 10 de outubro de 2007, constantes no Anexo IV da RENAME vigente no SUS; e municípios: R $\$ 2,36$ (dois reais e trinta e seis centavos) por habitante/ano, para financiar a aquisição dos medicamentos e insumos constantes dos Anexos I e IV da RENAME vigente no SUS, incluindo os insumos para os usuários insulinodependentes estabelecidos na Portaria $n^{\circ}$ 2.583/GM/MS, de 10 de outubro de 2007, constantes no Anexo IV da RENAME vigente no SUS ${ }^{(11)}$. 
Cabe ainda ao Ministério da Saúde o financiamento e a aquisição dos medicamentos contraceptivos e insumos do Programa Saúde da Mulher, constantes do Anexo I e IV da RENAME vigente ${ }^{(11)}$.

A execução do CBAF pode ser pactuada em Comissão Intergetora Bipartite (CIB) e a aquisição desses medicamentos pode se dar por formação de consórcios entre os municípios ou em aquisição de forma centralizada pelo Estado, o que acontece no estado do Ceará, onde dos 184 municípios do estado, apenas dois (Fortaleza/CE e Sobral/CE) não participam dessa modalidade de aquisição de medicamentos.

Considerando a necessidade de qualificar a AF, com ênfase na inserção das Redes de Atenção à Saúde, no âmbito do Sistema Único de Saúde, o Departamento de Assistência Farmacêutica do Ministério da Saúde (DAF/SCTIE/MS) formulou o programa QUALIFARSUS - Programa Nacional de Qualificação da Assistência Farmacêutica e pactuou o mesmo na Comissão Intergestores Tripartite do dia 26 de abril de 2012 com o Conselho Nacional de Secretários de Saúde (CONASS) e Conselho Nacional de Secretarias Municipais de Saúde (CONASEMS).

O Programa QUALIFAR-SUS foi regulamentado pela Portaria no 1.214, de 13 de junho 2012, do Ministério da Saúde. Tem por finalidade contribuir ao processo de aprimoramento, implementação e integração sistêmica das atividades da AF nas ações e serviços de saúde, visando uma atenção contínua, integral, segura, responsável e humanizada $^{(12)}$.

O QUALIFAR-SUS está organizado em quatro (4) eixos: Eixo Estrutura, Educação, Informação e Cuidado.

Todas as aquisições, obras e serviços contratados por órgãos da administração direta, os fundos especiais, as autarquias, as fundações públicas, as empresas públicas, as sociedades de economia mista e demais entidades controladas direta ou indiretamente pela União, Estados, Distrito Federal e Municípios devem ser precedidos de licitação, inclusive para ações e serviços da AF, ressalvadas as hipóteses previstas em lei.

A licitação destina-se a garantir a observância do princípio constitucional da isonomia, a seleção da proposta mais vantajosa para a administração e a promoção do desenvolvimento nacional sustentável e será processada e julgada em estrita conformidade com os princípios básicos da legalidade, da impessoalidade, da moralidade, da igualdade, da publicidade, da probidade administrativa, da vinculação ao instrumento convocatório, do julgamento objetivo e dos que lhes são correlatos ${ }^{(13)}$. 
São modalidades de licitação a concorrência, a tomada de preços, o convite, o concurso e o leilão. A Lei $\mathrm{n}^{\circ} 10.520$, de 17/7/02, instituiu, nova modalidade de licitação, o pregão, para aquisição de bens e serviços pela administração pública.

Segundo a lei N ${ }^{\circ}$ 8.666, as compras realizadas pela administração pública, sempre que possível, deverão atender ao princípio da padronização e ser processadas através de sistema de registro de preços.

O Ministério da Saúde e os respectivos órgãos vinculados poderão utilizar reciprocamente os sistemas de registro de preços para compras de materiais hospitalares, inseticidas, drogas, vacinas, insumos farmacêuticos, medicamentos e outros insumos estratégicos, desde que prevista tal possibilidade no edital de licitação do registro de preços. Os Estados, o Distrito Federal, os Municípios, bem como as respectivas autarquias, fundações e demais órgãos vinculados, também poderão utilizar-se dos registros de preços, desde que expressamente prevista esta possibilidade no edital de licitação ${ }^{(13)}$.

\subsection{Planejamento e Gestão da Assistência Farmacêutica no SUS}

Paim e Teixeira ${ }^{(14)}$ buscam identificar as inflexões que marcaram a produção de conhecimento em política, planejamento e gestão no Brasil, considerando as diversas conjunturas políticas e acadêmicas, e concluem que esta produção é marcada pelos desafios que exigem não só conhecimento técnico-científico, mas também militância sociopolítica. Alguns autores adotaram uma periodização que contempla diferentes fases em que os temas são incorporados segundo se apresentam novos desafios na trajetória política, fortemente marcada pela Reforma Sanitária e suas diferentes fases de implementação. Outros autores assinalam a existência de quatro correntes de planejamento/gestão em saúde, que não deixam de estar marcadas pelos desafios prático-teóricos e diversidade de influências teóricometodológicas: $1^{\circ}$ - A gestão estratégica do Laboratório de Planejamento (LAPA) da Faculdade de Medicina de Campinas defende um modelo de gestão colegiada e democrática; $2^{\circ}$ - O planejamento estratégico comunicativo, representado por núcleos da ENSP/Fiocruz, com base na teoria do agir comunicativo (TAC) de Habermas; $3^{\circ}$ - A corrente da Vigilância à Saúde, representada por um grupo heterogêneo do ponto de vista geográfico e institucional e $4^{\circ}$ - A escola da ação programática da Faculdade de Medicina da USP destacase pela ênfase a formas multidisciplinares de trabalho em equipe ${ }^{(15)}$.

Mintzberg ${ }^{(16)}$ estabelece uma diferenciação entre estratégia e planejamento. A estratégia seria o fruto de uma análise da alta gerência, a partir dum cálculo de síntese, 
baseado na intuição, na experiência e na necessidade imediata da ação. O planejamento, como cálculo analítico, seria um desdobramento operacional da estratégia. O perigo desta visão é recair numa concepção autoritária e centralizadora da estratégia, que se opõe a uma visão de planejamento comunicativo, na qual a estratégia é fruto da negociação entre atores plurais ${ }^{(15)}$.

Segundo Mendes, Manzini e Farias, 2015, a gestão da assistência farmacêutica enfrenta desafios para sua construção como uma área ligada ao sistema de saúde brasileiro, que garanta acesso e uso racional dos medicamentos, tendo o usuário como centro das atividades. Entendendo gestão como um processo técnico, político e social capaz de produzir resultados, sendo pautado, também, em princípios orientadores do Sistema Único de Saúde $(\mathrm{SUS})^{(17)}$.

A organização sistêmica da Assistência Farmacêutica caracteriza-se como uma estratégia que procura superar a fragmentação entre seus componentes e a fragmentação mais ampla, ainda presente no SUS, a fim de se efetivar como um serviço de saúde e tenta superar a visão que a AF é simplesmente executar as etapas do ciclo da Assistência Farmacêutica.

\subsection{Sistemas de informação na Assistência Farmacêutica}

Dentre tantos desafios para a administração pública no setor saúde, observa-se que a gestão da estrutura do setor saúde, a busca pelas melhores informações em tempo ágil e a utilização dessas informações, de forma efetiva, representam fatores essenciais para subsidiar a formulação e execução de políticas e programas voltados à melhoria das condições de vida da população brasileira ${ }^{(18)}$.

Diversos autores apontam que, para atender aos princípios que regem o SUS e cumprir os dispositivos legais, a definição de sistemas de informação em saúde, de âmbito nacional, deve ter a concepção discutida nas três instâncias de governo ${ }^{(19,20)}$.

Porém observa-se, historicamente, na área da saúde, uma política de informação de caráter prescritivo, normativo, não participativo, segmentado segundo a lógica de programas específicos, ocasionando pulverização dos sistemas de informação em saúde e ausência de comunicação entre instâncias central, regionais e locais, restringindo assim o papel dos estados, municípios e representações da sociedade na tomada de decisões ${ }^{(19,20)}$.

Observava-se, nacionalmente, a ausência ou carência de informações relativas à gestão, ao acesso, ao consumo e à utilização de medicamentos na rede pública de saúde. Diante de tais lacunas, em 2009, o Departamento de Assistência Farmacêutica e Insumos Estratégicos (DAF) do Ministério da Saúde (MS), responsável pela 
implantação, monitoramento e avaliação das Políticas Nacionais de Medicamentos e de Assistência Farmacêutica no Brasil, com a perspectiva de avançar na qualificação da Assistência Farmacêutica no SUS e contribuir para a gestão do cuidado, priorizou a formulação de uma inovação tecnológica voltada à gestão das informações do setor - o Sistema Nacional de Gestão da Assistência Farmacêutica - Hórus, caracterizando-a como uma iniciativa nacional, com proposta integradora.

O Sistema Hórus foi concebido para atender às singularidades da gestão da Assistência Farmacêutica no SUS, por meio dos seus componentes: básico, estratégico e especializado e teve o objetivo de qualificar a gestão e os serviços de Assistência Farmacêutica nos três níveis de governo, além de buscar aprimorar as ações de planejamento, desenvolvimento, monitoramento e avaliação, nessa modalidade de assistência à saúde ${ }^{(21)}$.

O sistema está integrado ao Cadastro Nacional de Saúde (Cartão do Sistema Único de Saúde - SUS), que permite a importação dos dados do usuário SUS e do Cadastro Nacional de Estabelecimentos de Saúde (CNES). Além disso, os bancos de dados das agências da Empresa de Correios e Telégrafos (ECT) e do Conselho Federal de Medicina (CFM) estão integrados ao Sistema, contribuindo tanto para o registro e atualização do endereço do usuário, como para o cadastramento do prescritor, na tela de dispensação.

O Hórus possibilita, ainda, o registro de medicamentos sob controle especial, uma parceria estabelecida com a Agência Nacional de Vigilância Sanitária - ANVISA. O Sistema emite diferentes relatórios, contendo informações gerenciais que subsidiam o planejamento e desenvolvimento das ações de Assistência Farmacêutica nos diferentes níveis de atenção: históricos das dispensações dos usuários; dados sobre pacientes faltosos; procedência das prescrições; posição de estoque; datas de agendamento das próximas dispensações; e outras.

Estão disponíveis informações técnicas necessárias para a qualificação dos serviços de Assistência Farmacêutica: RENAME; Formulário Terapêutico Nacional (FTN); Temas Selecionados para Promoção do Uso Correto de Medicamentos, de forma que possam ser utilizados durante o momento da prescrição e na dispensação, contribuindo com outras ferramentas da gestão do cuidado.

Além disso, por meio de uma parceria entre a Secretaria de Ciência e Tecnologia e Insumos Estratégicos (SCTIE), a Secretaria Especial de Saúde Indígena (SESAI) e a Secretaria de Gestão Estratégica e Participativa (SGEP), foi desenvolvido o módulo do Hórus para a gestão da Assistência Farmacêutica no Subsistema de Atenção à Saúde Indígena (SASISUS). O Hórus foi implantado nos trinta e quatro Distritos Sanitários Especiais 
Indígenas (DSEI), polos-base, Casas de Saúde do Índio (CASAI) e demais unidades de distribuição e dispensação de medicamentos do SASISUS. Com a informatização, é possível registrar as entradas, saídas e fluxo de produtos de medicamentos na rede de saúde indígena, contribuindo para o planejamento, monitoramento, avaliação e execução das ações da Assistência Farmacêutica, com vistas à ampliação do acesso da população indígena aos medicamentos essenciais.

Existem também outros sistemas de informação usados em Assistência Farmacêutica, como o SIGAF, usado em municípios de Minas Gerais e da Bahia, sistemas esses que apresentam funcionalidades semelhantes ao do Hórus.

\subsection{As Redes de Atenção à Saúde e a Assistência Farmacêutica}

Em relação ao perfil epidemiológico, o país vive uma transição singular, caracterizada por uma tripla carga de doenças que envolvem: a persistência de doenças parasitárias, infecciosas e desnutrição características de países subdesenvolvidos, embora com tendências de decréscimo; o aumento das doenças crônicas e seus fatores de risco, como sedentarismo, tabagismo, alimentação inadequada, obesidade e outros agravos; e o crescimento das causas externas, em decorrência do aumento da violência, dos acidentes de trânsito e acidentes de trabalho, homicídios e suicídios ${ }^{(20)}$.

Nesse contexto, os sistemas de atenção à saúde devem estar organizados para oferecer uma atenção contínua e integral a diferentes grupos populacionais, considerando suas características singulares de saúde, que envolvem fatores sociais, econômicos e culturais.

O modelo de atenção à saúde vigente, fundamentado nas ações curativas, centrado no cuidado médico e estruturado com ações e serviços de saúde dimensionados a partir da oferta, tem se mostrado insuficiente para superar os desafios sanitários atuais, e insustentável para os enfrentamentos futuros ${ }^{(22)}$.

O Ministério da Saúde, por meio da Política Nacional de Saúde, visa contribuir com a política de governo de diminuição das desigualdades regionais e combate à miséria. $\mathrm{O}$ Decreto no 7.508/2011, que regulamenta a Lei Orgânica da Saúde no 8.080/90, dispõe sobre a organização do SUS, o planejamento da saúde, a assistência à saúde e a articulação interfederativa e oferece novas perspectivas para o enfrentamento dos desafios $\operatorname{apontados}^{(23)}$.

Nesse escopo, o desenvolvimento das Redes de Atenção à Saúde (RAS), orientadas pela Portaria no 4.279/2010 e reforçada pelo Decreto no 7.508/2011, define-se como uma 
estratégia de reestruturação do sistema de saúde, tanto no que se refere à sua organização, quanto na qualidade e impacto na atenção prestada ${ }^{(22)}$.

Nessa portaria, a RAS é definida como:

"Arranjos organizativos de ações e serviços de saúde, de diferentes densidades tecnológicas, que integradas por meio de sistemas de apoio técnico, logístico e de gestão, buscam garantir a integralidade do cuidado. Fundamenta-se na compreensão da APS como primeiro nível de atenção, enfatizando a função resolutiva dos cuidados primários sobre os problemas mais comuns de saúde e a partir do qual se realiza e coordena o cuidado em todos os pontos de atenção. Os pontos de atenção a saúde são entendidos como espaços onde se ofertam determinados serviços de saúde, por meio de uma produção singular,"(22).

As RAS são constituídas pela população, que deve ser a razão de ser das mesmas.

A população de responsabilidade das redes de atenção à saúde vive em territórios sanitários singulares, organiza-se socialmente em famílias e é cadastrada e registrada em subpopulações por riscos sociossanitários. Assim, a população total de responsabilidade de uma rede de atenção à saúde deve ser plenamente conhecida e registrada em sistemas de informação potentes ${ }^{(22)}$.

Outro elemento constitutivo das RAS é a Estrutura Operacional, formada pelos nós das redes e pelas ligações materiais e imateriais que comunicam esses diferentes nós.

A estrutura operacional das redes de atenção à saúde compõe-se de cinco componentes: o centro de comunicação, a atenção primária à saúde; os pontos de atenção secundários e terciários; os sistemas de apoio; os sistemas logísticos; e o sistema de governança da rede de atenção à saúde. Os três primeiros correspondem aos nós das redes e o quarto, às ligações que comunicam os diferentes nós. E o quinto, o componente que governa as relações entre os quatro primeiros ${ }^{(22)}$.

Os sistemas de apoio são o terceiro componente constitutivo das RAS. São nesses lugares que se prestam serviços comuns a todos os pontos de atenção à saúde, tanto nos campos do apoio diagnóstico e terapêutico, da AF e nos sistemas de informação em saúde.

Os sistemas logísticos são soluções tecnológicas, fortemente ancoradas nas tecnologias de informação, que garantem uma organização racional dos fluxos e contra fluxos de informações, produtos e pessoas nas redes de atenção à saúde, permitindo um sistema eficaz de referência e contra referência das pessoas e trocas eficientes de produtos e informações, ao longo dos pontos de atenção à saúde e dos sistemas de apoio, nas redes de atenção à saúde. Os principais sistemas logísticos das redes de atenção à saúde são o cartão de identificação das pessoas usuárias, o prontuário clínico, os sistemas de acesso regulado à atenção à saúde e os sistemas de transporte em saúde ${ }^{(22)}$. 
O quinto componente das RAS são os sistemas de governanças, que é o arranjo organizativo que permite a gestão de todos os componentes das RAS, que sendo bem realizado, traz excelentes resultados para a população assistida.

E o terceiro elemento constitutivo das RAS são os modelos de atenção à saúde.

Os modelos de atenção à saúde são sistemas lógicos que organizam o funcionamento das redes de atenção à saúde, articulando, de forma singular, as relações entre a população e suas subpopulações estratificadas por riscos, os focos das intervenções do sistema de atenção à saúde e os diferentes tipos de intervenções sanitárias, definidos em função da visão prevalecente da saúde, das situações demográfica e epidemiológica e dos determinantes sociais da saúde, vigentes em determinado tempo e em determinada sociedade.

As RAS têm por finalidade garantir a integralidade da assistência à saúde, e a sua organização será aprimorada por meio dos Contratos Organizativos de Ação Pública (COAP), que devem observar a Relação Nacional de Ações e Serviços de Saúde (RENASES) e a Relação Nacional de Medicamentos Essenciais (RENAME).

Há, na literatura internacional, provinda de vários países, evidências de boa qualidade de que as redes de atenção à saúde podem melhorar a qualidade clínica, os resultados sanitários, a satisfação dos usuários e reduzir os custos dos sistemas de atenção à saúde ${ }^{(20)}$.

Consequentemente, desafios a serem superados estão propostos para a reestruturação do Sistema Único de Saúde, segundo a concepção das RAS, dentre as quais se destaca a integração das ações e serviços no campo da AF, que apresenta componentes de natureza técnica, científica, de inovação tecnológica e operativa, tendo por objeto a relação com o usuário, sendo que tais ações e serviços devem ser ordenados de acordo com a complexidade, necessidades da população e finalidades dos serviços de saúde.

Na Portaria $n^{\circ}$ 4.279/2010, a Assistência Farmacêutica é descrita como um dos elementos constituintes das Redes de Atenção à Saúde (RAS), enquanto sistema de apoio na estrutura operacional. Considerando que a AF desenvolve também serviços clínicos assistenciais, o Departamento de Assistência Farmacêutica e Insumos Estratégicos propõe uma reflexão desta portaria ${ }^{(5)}$.

\subsection{O QualiSUS-Rede}

O Projeto QualiSUS-Rede foi instituído como estratégia de apoio à organização das RAS no Brasil, com o objetivo de contribuir para a qualificação da atenção, gestão em saúde e gestão e desenvolvimento de tecnologias, por meio da organização de redes regionais e temáticas de atenção à saúde e da qualificação do cuidado em saúde ${ }^{(23)}$. 
As ações foram agrupadas em três componentes descritos no projeto disponível no Manual Operacional do QualiSUS-Rede, volume 1 Documento-Base ${ }^{(23)}$. Em relação ao Componente 2 - Desenvolvimento de intervenções sistêmicas e estratégicas, que tem por finalidade desenvolver um conjunto de intervenções sistêmicas de apoio à implantação de RAS e a qualificação do cuidado em saúde, destacam-se os seguintes eixos:

Eixo 1 - Apoio à estruturação e Qualificação das RAS

Eixo 2 - Gestão e Qualificação do Cuidado

Eixo 3 - Qualidade em Saúde

Eixo 4 - Inovação e Tecnologia em Saúde

Eixo 5 - Monitoramento e Avaliação de Subprojetos ${ }^{(23)}$.

Nesses eixos, enfatiza-se a necessidade de avançar na estruturação dos serviços farmacêuticos nas RAS, visando à qualificação da gestão e do cuidado. Compreende-se que as ações e serviços do Sistema de Assistência Farmacêutica são transversais às estruturas operacionais das RAS, conforme segue:

Sistema de Apoio: Objetiva garantir o abastecimento de medicamentos e insumos nos pontos de atenção, por meio da operacionalização das seguintes atividades: seleção, programação, aquisição, armazenamento, distribuição;

Fortalecer o ponto de comunicação com base na atenção básica: na estrutura operacional das RAS, a literatura e as experiências apontam para a busca pelo fortalecimento do centro de comunicação definido na atenção básica, e isso deve ocorrer principalmente quando forem idealizadas as plataformas para os sistemas de informação. Nesse sentido, pode-se avaliar positivamente a implantação do Sistema Hórus, pois à medida que o Hórus avança nos municípios, no tocante à implantação, e estes passam a utilizar sua principal funcionalidade, ou seja, a dispensação, as farmácias conseguem fornecer respostas às equipes de saúde, em especial para a atenção básica, a qual desempenha o papel de coordenadora do cuidado e ordenadora da rede;

Pontos de Atenção: Desenvolver atividades clínicas, em um trabalho articulado com a equipe de saúde, visando o uso correto dos medicamentos, contribuindo com a gestão do cuidado;

Sistema Logístico: Possibilitar a troca de informações ao longo dos pontos de atenção à saúde e dos sistemas de apoio na RAS em relação às ações da Assistência Farmacêutica;

Sistema de Governança: Contribuir para o monitoramento e avaliação das RAS por meio das informações relativas à Assistência Farmacêutica praticada ${ }^{(23)}$. 
Na fase inicial, destinou-se à implantação de 15 experiências de redes de atenção à saúde em alguns estados brasileiros, em todas as regiões brasileiras. Regiões que participaram do projeto:

- $\quad$ Região de Fronteira Internacional Ponta Porã/Dourados/MS

- $\quad$ Região do Alto Solimões/AM

- Região do Semiárido Cariri/CE

- $\quad$ Região Entre Rios/PI

- Região Integrada de Desenvolvimento do Distrito Federal e do Entorno RIDE/DF

- Região Interestadual do Bico do Papagaio - Tocantins/Pará/Maranhão TOPAMA

- $\quad$ Região Interestadual do Médio do Vale do São Francisco - Pernambuco/Bahia - PEBA

- $\quad$ Região Metropolitana de Belém/PA

- $\quad$ Região Metropolitana de Belo Horizonte/MG

- $\quad$ Região Metropolitana de Curitiba/PR

- Região Metropolitana de Florianópolis/SC

- $\quad$ Região Metropolitana de Porto Alegre/RS

- $\quad$ Região Metropolitana do Grande ABC/SP

- $\quad$ Região Metropolitana do Recife/PE

- $\quad$ Região Metropolitana do Rio de Janeiro/RJ

O Departamento de Assistência Farmacêutica (DAF/SCTIE/MS) elaborou o subprojeto "Intervenção Sistêmica da Assistência Farmacêutica nas Redes de Atenção à Saúde das Regiões Selecionadas do Projeto QualiSUS-Rede”, com o objetivo de qualificar a gestão da Assistência Farmacêutica das Regiões Metropolitanas e do projeto QualiSUS-Rede, por meio da formação profissional, informatização das unidades de saúde e utilização do Sistema Nacional de Gestão da Assistência Farmacêutica - Hórus como instrumento para a implementação do modelo de Redes de Atenção à Saúde ${ }^{(24)}$.

$\mathrm{Na}$ metodologia do QualiSUS-Rede, após o delineamento do método, que foi organizado em uma estrutura composta por quatro dimensões adaptadas do documento síntese para avaliação externa do Programa Nacional de Melhoria do Acesso e da Qualidade da Atenção Básica (PMAQ) e em três categorias de atividades farmacêuticas, relacionando 
com as variáveis eleitas como essenciais para a organização e efetivação da Assistência Farmacêutica nas Redes de Atenção à Saúde, além de uma dimensão de financiamento e suas variáveis, usou-se como variáveis da organização da Assistência Farmacêutica nas RAS de Atenção à Saúde, comuns para as categorias de serviços farmacêuticos técnico-gerenciais, técnico-assistenciais e gestão da Assistência Farmacêutica ${ }^{(23)}$.

A dimensão Gestão para o desenvolvimento da Assistência Farmacêutica sintetiza a organização, funcionamento, autonomia, execução e qualificação da Gestão da Assistência Farmacêutica, abrangendo ações de planejamento, intersetorialidade, acompanhamento, avaliação de resultados, acesso e utilização de informações relativa à prática da Assistência Farmacêutica, agregada à política de educação e gestão do trabalho que favoreçam a qualificação, provimentação e a fixação de trabalhadores atuando na Assistência Farmacêutica para suprir as necessidades de um efetivo funcionamento das ações e serviços na estrutura operacional das redes de atenção à saúde ${ }^{(17)}$. 


\section{MÉTODO}

Trata-se de uma análise de dados descritivos e quantitativos provenientes da pesquisa 'Assistência Farmacêutica nas Redes de Atenção à Saúde: um recorte nas regiões do QualiSUS-Rede', que teve como objetivo a identificação da situação dos serviços farmacêuticos, técnicos gerenciais e assistenciais nas 15 Regiões prioritárias do QualiSUSRede, de acordo com as diretrizes propostas para o funcionamento das Redes Regionais de Atenção à Saúde (RAS).

\section{Desenho do Estudo}

O estudo teve delineamento transversal, com coleta de dados de dezembro de 2013 a julho de 2015 em 485 municípios e Distrito Federal, de 43 regiões de saúde (http://sage.saude.gov.br/) que faziam parte das Regiões QualiSUS-Rede em setembro de 2013.

\section{Coleta de Dados}

Na coleta de dados primários foram utilizados cinco instrumentos conforme o perfil do entrevistado e do estabelecimento em questão, a saber: questionário para o Secretário da Saúde; questionário para o responsável pela Assistência Farmacêutica; questionário para o responsável pelo Ponto de Atenção e/ou Apoio Terapêutico (PA/PAT); questionário para o responsável pela Central de Abastecimento Farmacêutico (CAF); questionário para o responsável pela Farmácia Hospitalar (FH).

O instrumento de coleta foi aplicado em 485 municípios, contemplados em 17 estados apoiados pelos 15 subprojetos do QualiSUS-Rede, em todos os pontos de apoio terapêutico e pontos de atenção, assim como outros pontos relacionados aos serviços farmacêuticos, quais sejam: Centrais de Abastecimento Farmacêuticos (municipais e/ou estaduais), Centros de Atenção Psicossocial (CAPS), farmácias (com dispensação de medicamentos dos componente básico, estratégico ou especializado), farmácias populares do Brasil e hospitalares da rede própria, nas regiões com base nas informações da Sala de Apoio à Gestão Estratégica (SAGE), Censo de Unidades Básica de Saúde e Cadastro Nacional de Estabelecimentos de Saúde (CNES).

Os questionários foram aplicados por meio de aplicativo em dispositivo eletrônico móvel (tablet) a técnicos e gestores municipais e estaduais da Assistência Farmacêutica, no seu local de trabalho por Apoiadores Regionais em Assistência Farmacêutica do projeto 
QualiSUS-Rede, sob supervisão da equipe técnica do Departamento da Assistência Farmacêutica (DAF) e pelo supervisor do Projeto de Intervenção do Ministério da Saúde.

Para o presente estudo foi realizado um recorte e selecionada a Região Semiárido Cariri, no estado do Ceará, caracterizada conforme Quadro 1, por duas regiões de saúde composta por 19 municípios, correspondendo a uma população total de 751.362 habitantes, com municípios de 4.589 habitantes a 252.841 habitantes, todos fazendo parte do Plano Brasil Sem Miséria. A região em questão teve sua pesquisa de campo realizada no período de janeiro a maio de 2014 e os dados foram extraídos do aplicativo para compor a base de dados a ser analisada.

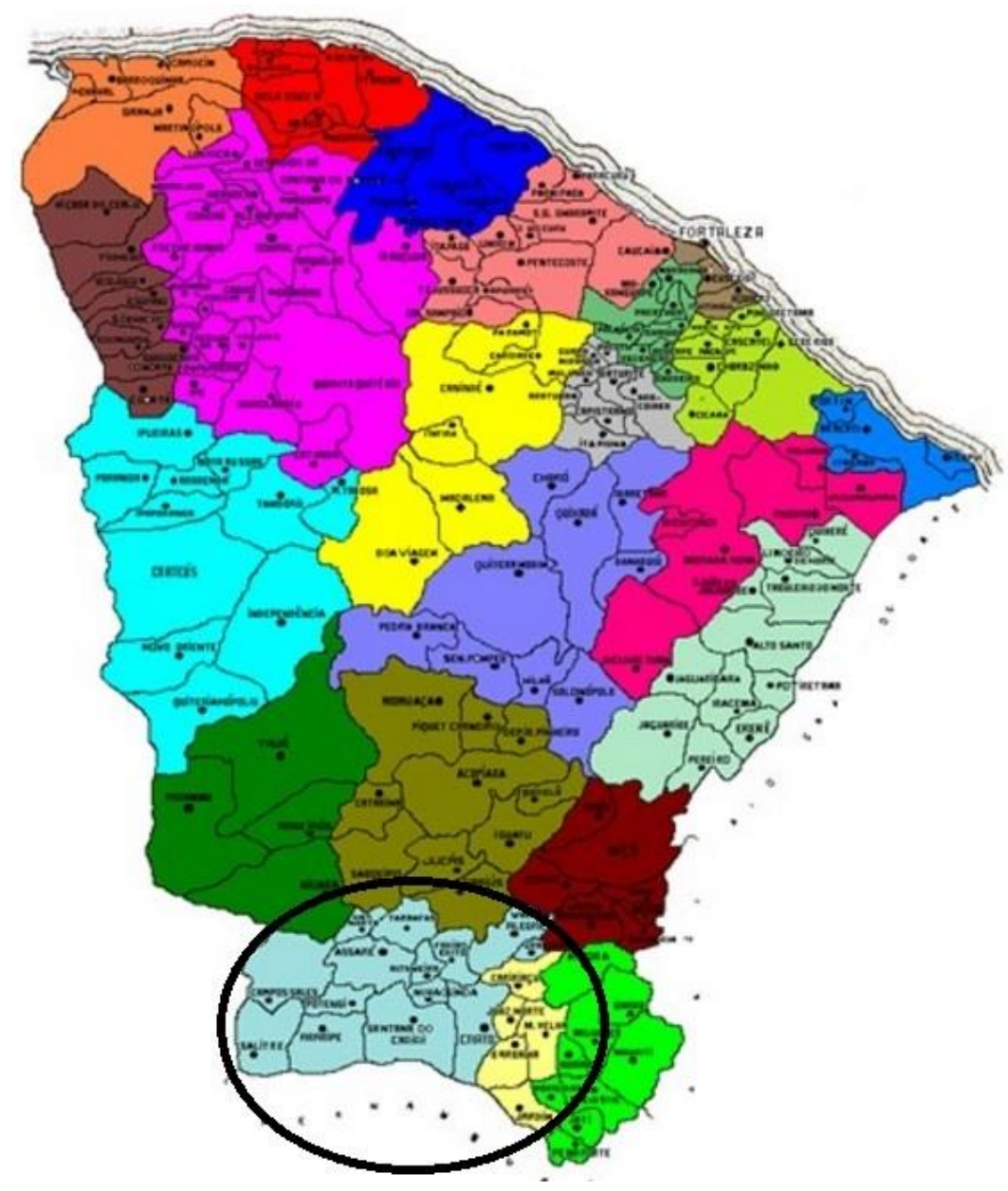

QUADRO 1 - REGIÃO SEMIÁRIDO CARIRI/CE

\begin{tabular}{|c|c|c|c|c|}
\hline \multirow{2}{*}{ ESTADO } & REGIÃO QUALISUS & REGIÃO DE SAÚDE & $\begin{array}{c}\text { TOTAL DE } \\
\text { MUNICÍPIOS }\end{array}$ & POPULAÇÃO \\
\hline & $\begin{array}{c}\text { Região Semiárido } \\
\text { Cariri/CE }\end{array}$ & $20^{\mathrm{a}}$ CRES Crato & 13 & 338.742 hab \\
\cline { 2 - 5 } & & $21^{\mathrm{a}}$ CRES Juazeiro do Norte & 6 & $412.620 \mathrm{hab}$ \\
\hline
\end{tabular}

Fonte: IBGE 2011 


\section{Análise dos Dados}

Considerando os objetivos do trabalho, foram analisados os dados oriundos dos questionários respondidos por responsáveis pela Assistência Farmacêutica (ANEXO) dos municípios da Região Semiárido Cariri/CE, com recorte das questões que envolvam a temática "Gestão da Assistência Farmacêutica".

Para tanto, as variáveis correspondentes foram selecionadas a fim de sintetizar a organização, funcionamento, autonomia, execução e qualificação da Gestão da Assistência Farmacêutica na região estudada, bem como o perfil do entrevistado quanto ao cargo, formação profissional e tipo de vínculo. No Quadro 2 estão apresentados os indicadores construídos a partir das variáveis de interesse nas categorias de análise.

A análise dos dados foi realizada pela inferência estatística descritiva e apresentada através de tabelas, onde foram calculadas as frequências absolutas simples e relativas, com suporte do sistema para análises estatísticas do programa estatístico SPPS 18.0.

A pesquisa foi aprovada pela CONEP por meio do parecer 399.423, de 18 de setembro de 2013. Todas as entrevistas foram precedidas de assinatura de Termo de Consentimento Livre e Esclarecido (TCLE).

QUADRO 2 - Quadro dos indicadores de acordo com as categorias de análise. QualiSUS Rede, 2015.

\begin{tabular}{|c|c|}
\hline CATEGORIA & INDICADORES \\
\hline \multirow{10}{*}{ AQUISIÇÃO E FINANCIAMENTO } & $\begin{array}{l}\text { Participação do farmacêutico na elaboração do Termo de } \\
\text { Referência (TR) para a aquisição de medicamentos }\end{array}$ \\
\hline & $\begin{array}{l}\text { Conhecimento da Portaria do Ministério da Saúde, em } \\
\text { vigência, a qual define as normas e execução do Financiamento } \\
\text { do Componente Básico da Assistência Farmacêutica }\end{array}$ \\
\hline & $\begin{array}{l}\text { Existência de cronograma de envio das informações para } \\
\text { programação da aquisição de medicamentos }\end{array}$ \\
\hline & $\begin{array}{l}\text { Suficiência do recurso total previsto na Portaria em vigência do } \\
\text { financiamento do Componente Básico da Assistência } \\
\text { Farmacêutica para adquirir todos os itens de medicamentos } \\
\text { padronizados nas quantidades adequadas }\end{array}$ \\
\hline & $\begin{array}{l}\text { Destinação pelo município de recursos financeiros da } \\
\text { contrapartida do Componente Básico da Assistência } \\
\text { Farmacêutica no valor total previsto em portaria, no ano } \\
\text { anterior }\end{array}$ \\
\hline & 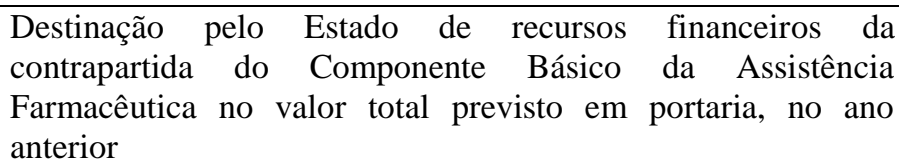 \\
\hline & $\begin{array}{l}\text { Utilização dos recursos orçados para aquisição de } \\
\text { medicamentos utilizados em sua totalidade, no ano anterior }\end{array}$ \\
\hline & $\begin{array}{l}\text { Existência de algum programa de co-financiamento da } \\
\text { Assistência Farmacêutica instituído }\end{array}$ \\
\hline & $\begin{array}{l}\text { Participação do responsável pela Assistência Farmacêutica na } \\
\text { elaboração do Plano Municipal de Saúde }\end{array}$ \\
\hline & Ações de Assistência Farmacêutica no último Relatório Anual \\
\hline
\end{tabular}




\begin{tabular}{|c|c|}
\hline \multirow{6}{*}{ PLANEJAMENTO } & de Gestão \\
\hline & $\begin{array}{l}\text { Recursos previstos e executados para a } \\
\text { Farmacêutica no último Relatório Anual de Gestão }\end{array}$ \\
\hline & $\begin{array}{l}\text { Previsão de recursos orçamentários na Lei Orçamentária Anual } \\
\text { (LOA), em vigência, específicos para a aquisição de } \\
\text { medicamentos }\end{array}$ \\
\hline & $\begin{array}{l}\text { Previsão de recursos orçamentários na Lei Orçamentária Anual } \\
\text { (LOA), em vigência, específicos para a estruturação da } \\
\text { Assistência Farmacêutica }\end{array}$ \\
\hline & $\begin{array}{l}\text { Previsão de recursos orçamentários na Lei Orçamentária Anual } \\
\text { (LOA), em vigência, específicos para o desenvolvimento das } \\
\text { ações da Assistência Farmacêutica, além do processo de } \\
\text { aquisição e estruturação }\end{array}$ \\
\hline & $\begin{array}{lccc}\text { Ações da Assistência Farmacêutica } & \text { contempladas } & \text { na } \\
\text { Programação Anual da Saúde } & & & \end{array}$ \\
\hline \multirow{3}{*}{ ESTRUTURAS FORMAIS } & $\begin{array}{l}\text { A Assistência Farmacêutica faz parte do organograma da } \\
\text { Secretaria Municipal de Saúde (SMS) }\end{array}$ \\
\hline & $\begin{array}{l}\text { Existência de uma Comissão de Licitação Permanente no } \\
\text { município }\end{array}$ \\
\hline & $\begin{array}{l}\text { Comissão de Farmácia e Terapêutica (CFT) formalmente } \\
\text { constituída na Secretaria Municipal de Saúde }\end{array}$ \\
\hline \multirow{2}{*}{$\begin{array}{c}\text { SISTEMA DE INFORMAÇÃO DA ASSISTÊNCIA } \\
\text { FARMACÊUTICA }\end{array}$} & $\begin{array}{l}\text { Existência de um sistema informatizado para a gestão da } \\
\text { Assistência Farmacêutica }\end{array}$ \\
\hline & $\begin{array}{l}\text { Existência de sistema informatizado em rede com as Unidades } \\
\text { de Saúde }\end{array}$ \\
\hline
\end{tabular}

Fonte: Elaboração própria 


\title{
6. RESULTADOS E DISCUSSÕES \\ 6.1 ARTIGO
}

\section{GESTÃo DA ASSISTÊnCIA FARMACÊUTICA EM REGIÕES DE SAÚdE DO CEARÁ: um recorte do Projeto QualiSUS-Rede}

\section{PHARMACEUTICAL SERVICES MANAGEMENT IN CEARÁ HEALTH REGIONS: a cut of QualiSUS-Network Project}

\section{SERVICIO DE GESTIÓN FARMACÉUTICA EN LAS REGIONES DE SALUD DEL Ceará: un corte de QualiSUS-Red del Plan}

\section{Resumo}

Esse artigo tem por objetivo descrever a caracterização da gestão da Assistência Farmacêutica em regiões de saúde da Região Semiárido Cariri/CE quanto as suas estruturas formais, serviços farmacêuticos técnicos gerenciais ofertados e/ou praticados, por meio de informações obtidas com o Projeto QualiSUS-Rede. Foram entrevistados os responsáveis pela Assistência Farmacêutica em 19 municípios. Entre os resultados destaca-se que a Assistência Farmacêutica faz parte do organograma da Secretaria Municipal de Saúde em 84,2\% dos municípios. Em relação ao financiamento, foi referido por $68,4 \%$ dos responsáveis insuficiência do recurso do Componente Básico da Assistência Farmacêutica para aquisição de medicamentos padronizados, entretanto a grande parte referiu que não foi aplicado o valor mínimo pactuado tanto pelo município $(21,1 \%)$ como pelo Estado $(31,6 \%)$. Nenhum dos municípios realizam monitoramento e avaliação da Assistência Farmacêutica por meio de indicadores. Esperamos, com os resultados observados nesse estudo, contribuir para a melhoria da gestão da Assistência Farmacêutica, visando a promoção do acesso aos medicamentos a população das regiões de saúde.

Palavras-chave: Sistemas de Saúde; Gestão; Assistência Farmacêutica

\begin{abstract}
This article aims to describe the characterisation of the Pharmaceutical Service in the health regions of the Semiarid Cariri/CE Region, in relation to its formal structures, pharmaceutical technical management services offered and/or practised with information obtained through the project QualiSUS-Rede [QualiSUS-Network]. People from 19
\end{abstract}


municipalities who are responsible for the PA were interviewed. Some of the most remarkable results show that Pharmaceutical Service is part of the Municipal Secretariat of Health organization chart in $84.2 \%$ of the municipalities. Regarding funding, $68.4 \%$ of those responsible for the PA stated the Basic Component of Pharmaceutical Assistance had insufficient resources to acquire standardized medicines, however, most of them said the minimum price was not applied neither by the municipality $(21.1 \%)$ nor by the State $(31.6 \%)$. None of the municipalities supervise or evaluate the Pharmaceutical Assistance by means of indicators. Through this research we hope to contribute to the improvement of the Pharmaceutical Assistance management, and aim at promoting the access to medicines by the population from the health regions.

Keywords: Health Systems; management; Pharmaceutical Service

\section{Resumen}

Este artículo tiene como objetivo es describir la caracterización de la gestión de la Asistencia Farmacéutica en regiones de salud de la Región Semiárida Cariri/CE en relación a sus estructuras formales, servicios farmacéuticos técnicos gerenciales ofertados y/o practicados, através de información obtenida con el Proyecto QualiSUS-Rede. Fueron entrevistados los responsables por la Asistencia Farmacéutica de 19 municipios. Entre los resultados podemos destacar que la AF forma parte del organigrama de la Secretaría Municipal de Salud en $84,2 \%$ de los municipios. En relación al financiamiento, fue mencionado por el $68,4 \%$ de los responsables por la AF una insuficiencia del recurso del Componente Básico de Asistencia Farmacéutica para la adquisición de medicamentos estandarizados, sin embargo la mayoría relató que no fue aplicado el valor mínimo ni por los municipios $(21,1 \%)$ ni por el Estado $(31,6 \%)$. Ningún municipio supervisa ni evalúa la Asistencia Farmacéutica a través de indicadores. Esperamos, con los resultados contemplados en este estudio, contribuir a mejorar la gestión de la Asistencia Farmacéutica, visando la promoción del acceso a los medicamentos por parte de la población de las regiones de salud.

Descriptores: Sistemas de Salud; Géstion; Asistencia Farmacéutica 


\section{Introdução}

O Sistema Único de Saúde (SUS), instituído por meio da Lei Orgânica da Saúde $(1990)^{(1)}$, tem como objetivo assegurar o acesso da população aos serviços de promoção, proteção e recuperação da saúde deflagrou o processo de elaboração de um conjunto de políticas públicas relativas à saúde. Inserem-se nesse conjunto a Política Nacional de Medicamentos, de 1998, e a Política Nacional de Assistência Farmacêutica, de 2004, promulgadas com o propósito de garantir o acesso a medicamentos aliado à promoção de seu uso racional e construir um arcabouço legal para sustentar o processo de descentralização da gestão das ações da Assistência Farmacêutica no SUS ${ }^{(2)}$

A Assistência Farmacêutica vem sendo implementada de forma articulada entre os gestores do SUS, sendo a responsabilidade pelo seu financiamento das três esferas de gestão do SUS (federal, estadual, municipal), e a sua execução e responsabilidades pactuadas nas instâncias intergestoras com o objetivo de organizar as atividades relacionadas à gestão dos medicamentos, visando garantir o acesso da população ${ }^{(3)}$.

Se por um lado, temos um avanço e consolidação legal da Assistência Farmacêutica estruturada pelas respectivas leis e portarias, que norteiam e contribuem para uma melhor organização da AF nos municípios, observa-se ainda problemas referentes a gestão dos recursos e/ou de serviços farmacêuticos, seja por má utilização dos recursos financeiros, ausência de planejamento e programação para a aquisição de medicamentos; e o armazenamento em condições inapropriadas ocasionando perdas de medicamentos ${ }^{(2,4)}$.

Os desafios atuais para a gestão da assistência farmacêutica de ultrapassar a visão procedimental e minimalista do ciclo gerencial, passando a ter o usuário como centro das atividades é reforçada pela demanda crescente por medicamentos que envolve elevado aporte de recursos financeiros para garantir à população, o acesso regular aos medicamentos e ao mesmo tempo a necessidade de otimização da terapêutica ofertada com a promoção do uso 
racional dos medicamentos. Portanto, a Assistência Farmacêutica, exerce um importante papel no setor produtivo, na inovação e no desenvolvimento tecnológico e, de outro lado, é essencial na produção de serviços, propiciando integralidade e resolutividade às ações de saúde ${ }^{(5)}$.

Neste contexto, esse trabalho tem por objetivo caracterizar a gestão da Assistência Farmacêutica quanto as suas estruturas formais, os serviços farmacêuticos técnicos gerenciais ofertados e/ou praticados em municípios das regiões de saúde da Região do Semiárido do Cariri/CE.

\section{Métodos}

Trata-se de um estudo descritivo com dados provenientes da pesquisa 'Assistência Farmacêutica nas Redes de Atenção à Saúde: um recorte nas regiões do QualiSUS-Rede', que teve como objetivo a identificação da situação dos serviços farmacêuticos, técnicos gerenciais e assistenciais nas 15 Regiões prioritárias do QualiSUS-Rede, de acordo com as diretrizes propostas para o funcionamento das Redes Regionais de Atenção à Saúde (RAS).

O estudo teve delineamento transversal, com coleta de dados de dezembro de 2013 a julho de 2015 em 485 municípios e Distrito Federal, de 43 regiões de saúde (http://sage.saude.gov.br/) que faziam parte das Regiões QualiSUS-Rede em setembro de 2013.

Para o presente artigo foi realizado um recorte da Região QualiSUS-Rede do Semiárido Cariri, no estado do Ceará, caracterizada por duas regiões de saúde composta por 19 municípios, correspondendo a uma população total de 751.362 habitantes, com municípios de 4.589 habitantes a 252.841 habitantes, todos fazendo parte do Plano Brasil Sem Miséria.

Foram incluídos na análise os questionários respondidos pelos responsáveis pela Assistência Farmacêutica, dos municípios da Região Semiárido Cariri/CE, com recorte das questões relacionadas a temática "Gestão da Assistência Farmacêutica". O instrumento foi aplicado por meio de aplicativo em dispositivo eletrônico móvel (tablet) por apoiadores regionais em Assistência Farmacêutica do projeto QualiSUS-Rede previamente treinados.

As variáveis de interesse foram trabalhadas em indicadores (QUADRO 1) conforme as categorias de análise a fim de sintetizar aspectos relacionados a organização, funcionamento, autonomia e execução da gestão da Assistência Farmacêutica na região estudada, bem como o perfil do entrevistado quanto a formação profissional e tipo de vínculo. Foi realizada a análise 
descritiva e calculados os percentuais dos indicadores analisados utilizando o programa estatístico SPPS 18.0.

O estudo foi aprovado pelo Comitê Nacional de Ética em Pesquisa (CONEP). Parecer

399.423 de 18 de setembro de 2013. Todas as entrevistas foram precedidas de assinatura de

Termo de Consentimento Livre e Esclarecido (TCLE).

QUADRO 1 - Quadro dos indicadores de acordo com as categorias de análise. QualiSUS Rede, 2015.

\begin{tabular}{|c|c|}
\hline CATEGORIA & INDICADORES \\
\hline \multirow{8}{*}{ AQUISIÇÃO E FINANCIAMENTO } & $\begin{array}{l}\text { Participação do farmacêutico na elaboração do Termo de } \\
\text { Referência (TR) para a aquisição de medicamentos }\end{array}$ \\
\hline & $\begin{array}{l}\text { Conhecimento da Portaria do Ministério da Saúde, em } \\
\text { vigência, a qual define as normas e execução do Financiamento } \\
\text { do Componente Básico da Assistência Farmacêutica }\end{array}$ \\
\hline & $\begin{array}{l}\text { Existência de cronograma de envio das informações para } \\
\text { programação da aquisição de medicamentos }\end{array}$ \\
\hline & $\begin{array}{l}\text { Suficiência do recurso total previsto na Portaria em vigência do } \\
\text { financiamento do Componente Básico da Assistência } \\
\text { Farmacêutica para adquirir todos os itens de medicamentos } \\
\text { padronizados nas quantidades adequadas }\end{array}$ \\
\hline & $\begin{array}{l}\text { Destinação pelo município de recursos financeiros da } \\
\text { contrapartida do Componente Básico da Assistência } \\
\text { Farmacêutica no valor total previsto em portaria, no ano } \\
\text { anterior }\end{array}$ \\
\hline & $\begin{array}{l}\text { Destinação pelo Estado de } \text { recursos } \\
\text { contrapartida do Componente } \text { Básico da Assistência } \\
\text { Farmacêutica no valor total previsto em portaria, no ano } \\
\text { anterior }\end{array}$ \\
\hline & $\begin{array}{l}\text { Utilização dos recursos orçados para aquisição de } \\
\text { medicamentos utilizados em sua totalidade, no ano anterior }\end{array}$ \\
\hline & $\begin{array}{l}\text { Existência de algum programa de co-financiamento da } \\
\text { Assistência Farmacêutica instituído }\end{array}$ \\
\hline \multirow{7}{*}{ PLANEJAMENTO } & $\begin{array}{l}\text { Participação do responsável pela Assistência Farmacêutica na } \\
\text { elaboração do Plano Municipal de Saúde }\end{array}$ \\
\hline & $\begin{array}{l}\text { Ações de Assistência Farmacêutica no último Relatório Anual } \\
\text { de Gestão }\end{array}$ \\
\hline & $\begin{array}{l}\text { Recursos previstos e executados para a Assistência } \\
\text { Farmacêutica no último Relatório Anual de Gestão }\end{array}$ \\
\hline & $\begin{array}{l}\text { Previsão de recursos orçamentários na Lei Orçamentária Anual } \\
\text { (LOA), em vigência, específicos para a aquisição de } \\
\text { medicamentos }\end{array}$ \\
\hline & $\begin{array}{l}\text { Previsão de recursos orçamentários na Lei Orçamentária Anual } \\
\text { (LOA), em vigência, específicos para a estruturação da } \\
\text { Assistência Farmacêutica }\end{array}$ \\
\hline & $\begin{array}{l}\text { Previsão de recursos orçamentários na Lei Orçamentária Anual } \\
\text { (LOA), em vigência, específicos para o desenvolvimento das } \\
\text { ações da Assistência Farmacêutica, além do processo de } \\
\text { aquisição e estruturação }\end{array}$ \\
\hline & $\begin{array}{l}\text { Ações da Assistência Farmacêutica } \\
\text { Programação Anual da Saúde }\end{array}$ \\
\hline \multirow[t]{2}{*}{ ESTRUTURAS FORMAIS } & $\begin{array}{l}\text { A Assistência Farmacêutica faz parte do organograma da } \\
\text { Secretaria Municipal de Saúde (SMS) }\end{array}$ \\
\hline & $\begin{array}{l}\text { Existência de uma Comissão de Licitação Permanente no } \\
\text { município }\end{array}$ \\
\hline
\end{tabular}




\begin{tabular}{|c|l|}
\hline & $\begin{array}{l}\text { Comissão de Farmácia e Terapêutica (CFT) formalmente } \\
\text { constituída na Secretaria Municipal de Saúde }\end{array}$ \\
\hline \multirow{3}{*}{$\begin{array}{c}\text { SISTEMA DE INFORMAČ̃̃O DA ASSISTÊNCIA } \\
\text { FARMACÊUTICA }\end{array}$} & $\begin{array}{l}\text { Existência de um sistema informatizado para a gestão da } \\
\text { Assistência Farmacêutica }\end{array}$ \\
\cline { 2 - 2 } & $\begin{array}{l}\text { Existência de sistema informatizado em rede com as Unidades } \\
\text { de Saúde }\end{array}$ \\
\hline
\end{tabular}

Fonte: Elaboração própria

\section{Resultados e discussão}

Foram entrevistados todos responsáveis pela Assistência Farmacêutica dos municípios das regiões de saúde investigadas (n=19), desses sendo 17 farmacêuticos, e no que se refere a vínculo empregatício, $42,1 \%$ eram contratados, $31,6 \%$ eram comissionados e 26,3\% concursados.

Pelos resultados (Tabela 1) podemos observar que em 15,8\% dos municípios foi referido a participação do farmacêutico na elaboração do Termo de Referência para a aquisição de medicamentos e quando perguntado pela existência de cronograma de envio das informações para programação da aquisição de medicamentos, somente 31,6\% afirmaram que sim. A programação de medicamentos deve ser ascendente para refletir as necessidades locais a fim de evitar aquisições distorcidas e problemas de desabastecimento e perdas de medicamentos. As deficiências neste componente de gestão podem concorrer para aumentar os riscos de desperdício e de desabastecimento, comprometendo todos os demais componentes da gestão da Assistência Farmacêutica, resultando em sérios transtornos à população, pela falta de acesso aos medicamentos de que precisa ${ }^{(4)}$.

A Portaria $\mathrm{N}^{\mathrm{o}} 1.555^{(6)}$, de 30 de julho de 2013, dispõe sobre as normas de financiamento e de execução do Componente Básico da Assistência Farmacêutica (CBAF) no âmbito do Sistema Único de Saúde (SUS). Segundo essa Portaria, o financiamento do CBAF é de responsabilidade da União, dos Estados, do Distrito Federal e dos Municípios, com aplicação, no mínimo, dos seguintes valores de seus orçamentos próprios: União: $\mathrm{R} \$ 5,10$ (cinco reais e dez centavos) por habitante/ano; Estados: $\mathrm{R} \$ 2,36$ (dois reais e trinta e seis centavos) por habitante/ano e Municípios: $\mathrm{R} \$ 2,36$ (dois reais e trinta e seis centavos) por habitante/ano, para financiar a aquisição dos medicamentos e insumos constantes dos Anexos I e IV da RENAME vigente no SUS, incluindo os insumos para os usuários insulinodependentes.

Quando perguntado se o recurso total previsto, na Portaria em vigência do financiamento do Componente Básico da Assistência Farmacêutica, é suficiente para adquirir todos os itens de medicamentos padronizados nas quantidades adequadas (Tabela 1), 68,4\% 
dos entrevistados afirmaram que não. Por outro lado, quando perguntado se os municípios destinaram recursos financeiros da contrapartida do Componente Básico da Assistência Farmacêutica no valor total previsto em portaria, no ano de 2013 (Tabela 1), 73,7\% responderam que sim. Para mais da metade dos municípios, 63,2\%, o Estado destinou recursos financeiros da contrapartida do Componente Básico da Assistência Farmacêutica no valor total previsto em portaria, no ano anterior (Tabela 1).

Os resultados demonstram que a aplicação do mínimo pactuado para o financiamento da AF não está sendo efetivado na totalidade dos municípios, apontando para a necessidade de reforçar as responsabilidades interfederativas no financiamento da AF nas regiões estudadas. Ressalta-se que a aplicação da contrapartida estadual e/ou municipal em desacordo com a pactuação e a ausência de controle de estoque ou deficiência, podem impactar no acesso a medicamentos pela população atendida ${ }^{(7)}$.

Em estudo realizado no Estado da Paraíba ${ }^{(4)}$, foi evidenciado que dentre os fatores que dificultam a efetivação das ações sistemáticas da Assistência Farmacêutica é a falta de contrapartida da Secretaria Estadual de Saúde para o Programa Farmácia Básica, constatada em 20\% dos municípios paraibanos, bem como a falta de contrapartida da Secretaria Municipal de Saúde para o referido Programa, em 9,1\% dos municípios auditados. Verificase, portanto, que tanto os Estados como os municípios não vêm assumindo de forma sistemática as contrapartidas sob sua responsabilidade, conforme determina legislação vigente. Isso promove um descumprimento das normas legais, e traz prejuízos e transtornos para o sistema de saúde e para a população assistida.

Outro fator relevante é que apesar dos responsáveis pela AF dos municípios terem referido insuficiência de recursos para aquisição de medicamentos e a não aplicação do total pactuado para o CBAF pelos entes, os recursos orçados para aquisição de medicamentos não foram utilizados em sua totalidade no ano anterior em cerca de um terço dos municípios, apontando fragilidade no processo de gestão da AF na região.

Quando perguntado se existe algum programa de co-financiamento da Assistência Farmacêutica instituída (Tabela 1), 57,9\% dos entrevistados afirmaram que sim. No Estado do Ceará é pactuada em CIB (Resolução 355/2012) o financiamento da Assistência Farmacêutica na Atenção Secundária de responsabilidade das esferas estadual e municipal, em que são aplicados os valores per capita habitante/ano mínimos para aquisição de medicamentos do Elenco da Atenção Secundária de R \$ 1,00 (um real) do Governo Estadual e pelo Governo Municipal de $\mathrm{R} \$ 1,50$ à $\mathrm{R} \$ 2,00$ (um real e cinquenta centavos à dois reais). 
O responsável pela Assistência Farmacêutica referiu participar da elaboração do Plano Municipal de Saúde em boa parte dos municípios, 63,2\% (Tabela 2). Em estudo de Mendes $(2015)^{(8)}$, observou-se que no indicador que verificava se o coordenador da Assistência Farmacêutica, que estava na época da construção do Plano Municipal de Saúde, participou da elaboração do documento, obteve-se a pontuação máxima (10), no entanto, $60 \%$ dos farmacêuticos entrevistados não conheciam o Plano Municipal de Saúde.

Com relação ao último Relatório Anual de Gestão (RAG) (Tabela 2), em apenas em 26,3\% dos municípios foi referido que as ações da Assistência Farmacêutica foram descritas no mesmo, e quanto à descrição dos recursos previstos e executados para a Assistência Farmacêutica em apenas 15,8\% informado a sua presença, sendo que a grande maioria dos responsáveis desconheciam a presença destas informações no último RAG. Importante destacar que o Relatório Anual de Gestão é o instrumento de planejamento que apresenta os resultados alcançados com a execução da Programação Anual de Saúde, apurados com base no conjunto de ações, metas e indicadores desta, e orienta eventuais redirecionamentos que se fizerem necessários ao Plano de Saúde e às Programações seguintes ${ }^{(9)}$

Em relação aos recursos orçamentários previstos para a aquisição de medicamentos na Lei Orçamentária Anual (LOA) em vigência, 26,3\% dos municípios responderem que sim. Em apenas dois municípios, 10,5\%, na Lei Orçamentária Anual (LOA) em vigência, está previsto recursos orçamentários específicos para a estruturação da Assistência Farmacêutica e em 5,3\% dos municípios está previsto recursos orçamentários específicos para o desenvolvimento das ações da Assistência Farmacêutica, além do processo de aquisição e estruturação (Tabela 2).

Em menos da metade dos municípios $(47,4 \%)$ foi informado que as ações da Assistência Farmacêutica estão contempladas na Programação Anual da Saúde (PAS) (Tabela 2), que contém, de forma sistematizada, as ações, os recursos financeiros e outros elementos que contribuem para o alcance dos objetivos e o cumprimento das metas do Plano de Saúde, as metas anuais para cada ação definida, os indicadores utilizados no monitoramento e na avaliação de sua execução. Sua elaboração inicia no ano em curso, para execução no ano subsequente e é fundamental para o planejamento municipal.

No estudo de Bruns SF (2014) ${ }^{(4)}$, observou-se a "inexistência de um Plano Municipal de Assistência Farmacêutica Básica" em 12,7\% dos municípios, evidenciando, portanto, a falta de uma programação das necessidades decorrentes do perfil nosológico da população, que visa assegurar o suprimento dos medicamentos destinados à atenção básica à saúde da 
população, integrando sua programação à do Estado, com foco no abastecimento permanente e oportuno.

A Assistência Farmacêutica faz parte do organograma da Secretaria Municipal de Saúde na maioria dos municípios, cerca de $84,2 \%$ (Tabela 3), e a coordenação dessa AF é realizada por farmacêuticos (as) em 89,5\% deles (dado não apresentado em tabela). Esse resultado mostra um panorama melhor que o estudo realizado por Vieira ${ }^{(10)}$ onde ele demonstrou que $44,4 \%$ dos município que participaram da sua pesquisa informaram ter a Assistência Farmacêutica formalizada, ou seja, prevista no organograma formal da secretaria de saúde.

A maioria dos municípios (Tabela 3), 94,7\%, apresentam uma Comissão de Licitação Permanente. Apenas um município não sabia dizer se o município apresentava tal comissão. Segundo a Lei $\mathrm{N}^{\circ} 8.666^{(11)}$, de 21 de junho de 1993, que regulamenta o Art. 37, inciso XXI, da Constituição Federal, institui normas para licitações e contratos da Administração Pública e dá outras providências, Comissão de Licitação Permanente é criada pela Administração com a finalidade de receber, examinar e julgar todos os documentos e procedimentos relativos às licitações e ao cadastramento de licitantes.

Estudo recente ${ }^{(4)}$, verificou que $52,7 \%$ dos municípios paraibanos não observavam as normas de aquisição de medicamentos, o que constitui uma das principais falhas ou irregularidades encontradas nas licitações públicas. Nesse mesmo estudo foi possível constatar que em 16,36\% dos municípios, a "aquisição de medicamentos ocorreu com preço superior ao do fornecedor ou ao banco de preços em saúde", situação que caracteriza, no mínimo, a ausência de realização de pesquisa de preços para definição do valor unitário máximo a ser contratado pelo município para a aquisição dos medicamentos. E ainda constatou-se que em 14,5\% dos municípios estudados, a "aquisição de medicamentos ocorreu sem o processo licitatório", o que denota irregularidades no processo de aquisição de medicamentos de acordo com legislação vigente.

Segundo os responsáveis pela AF, em menos da metade $(42,1 \%)$ dos municípios o Plano Municipal de Saúde contemplava ações para a Educação Permanente para a Assistência Farmacêutica. Destaca-se que o Plano Municipal de Saúde, é um instrumento de profissionalização e de transparência das políticas de saúde, que deve contemplar todo planejamento da saúde do município, inclusive o que tange educação permanente para todos os envolvidos, entre eles os profissionais da Assistência Farmacêutica. 
Quando indagados, os responsáveis pela Assistência Farmacêutica, sobre o conhecimento da Portaria do Ministério da Saúde, em vigência, a qual define as normas e execução do Financiamento do Componente Básico da Assistência Farmacêutica (Tabela 3), $78,9 \%$ afirmaram conhecer.

Já em relação ao conhecimento da Resolução da Comissão Intergestores Bipartite (CIB), em vigência, a qual define normas para a execução do Financiamento do Componente Básico da Assistência Farmacêutica no Estado (Tabela 3), quase 89,5\% disseram conhecer. A execução do CBAF pode ser pactuada em CIB e a aquisição desses medicamentos pode se dar por formação de consórcios entre os municípios ou em aquisição de forma centralizada pelo Estado, o que acontece no estado do Ceará, onde dos 184 municípios do Estado, em 2014, apenas dois não participam dessa modalidade de aquisição de medicamentos.

Um resultado relevante observado foi com relação aos sistemas de gerenciamento de informações por parte dos municípios, onde quase todos, 94,7\%, utilizam sistema de informação para gestão da Assistência Farmacêutica. Este resultado é relevante, diante dos dados encontrados em outros estudos que demonstram fragilidades no processo de controle de estoque nos municipios. No estudo de Vieira ${ }^{(10)}, 27,8 \%$ dos municípios ainda fazem controle inadequado, sem garantia do monitoramento das entradas e saídas diárias dos medicamentos, seja por meio de fichas de prateleira, planilha eletrônica ou sistema informatizado. Estudo publicado em $2008^{(7)}$, o qual analisou amostra de $10,7 \%$ dos municípios brasileiros $(\mathrm{n}=597)$, encontrou que em $71 \%$ dos municípios ou faltava mecanismo para controle de estoque ou este era deficiente, e no estudo de Bruns ${ }^{(4)}$ constatou-se que $52,7 \%$ dos municípios apresentaram um "controle de estoque deficiente ou inexistente".

É importante destacar, que todos os municípios que referiram utilizar sistemas informatizados para a gestão, utilizam o Sistema HORUS (Tabela 3). O Sistema Hórus foi concebido para atender às singularidades da gestão da Assistência Farmacêutica no SUS, por meio dos seus componentes: básico, estratégico e especializado e teve o objetivo de qualificar a gestão e os serviços de Assistência Farmacêutica nos três níveis de governo, além de buscar aprimorar as ações de planejamento, desenvolvimento, monitoramento e avaliação, nessa modalidade de assistência à saúde ${ }^{(12)}$. Entretanto, cabe destacar que somente em $10,5 \%$ dos municípios (Tabela 3) o sistema informatizado está em rede com as Unidades de Saúde. Os sistemas de gerenciamento de informação na Assistência Farmacêutica fornecem informações que contribuem com o planejamento e favorecem melhores intervenções nesse setor das RAS. 
Com relação a presença de Comissão de Farmácia e Terapêutica (CFT) formalmente constituída na Secretaria Municipal de Saúde, observou-se que nenhum dos 19 municípios a tem. Segundo Marin et al $^{(13)}$, Comissão de Farmácia e Terapêutica tem, entre seus objetivos, assessorar a formulação e implementação de políticas entre outras voltadas para a seleção, programação, prescrição, dispensação e uso racional de medicamentos sendo instâncias responsáveis pela avaliação do uso clínico dos medicamentos, desenvolvendo políticas para gerenciar o uso, a administração e o sistema de seleção.

Em estudo de Assunção ${ }^{(14)}$, observou-se que $29 \%$ dos municípios possuem CFT: nestes, todos têm farmacêuticos em sua constituição. Nos municípios que não possuem CFT organizada, os profissionais que realizam a seleção de medicamentos são farmacêuticos, médicos, enfermeiros, secretários de saúde. Em apenas um município o farmacêutico não participa do processo de seleção de medicamentos.

Não foi informado por nenhum responsável pela Assistência Farmacêutica dos municípios a utilização de indicadores para o monitoramento e avaliação da Assistência Farmacêutica, identificando uma lacuna importante na gestão. Alguns autores ${ }^{(15,16)}$ reforçam a importância dessas informações para a formulação e execução de políticas e programas locais e que a utilização de indicadores é uma estratégia fundamental de organização da atenção e gestão em saúde para a avaliação das ações desenvolvidas pela Assistência Farmacêutica nos municípios.

\section{Considerações Finais}

Os resultados apontam alguns avanços na gestão da Assistência Farmacêutica nos municípios investigados, como a existência de uma coordenação de Assistência Farmacêutica formalmente constituída na grande parte dos municípios e a utilização de ferramentas informatizadas como suporte a gestão. Entretanto lacunas importantes foram evidenciadas como a baixa participação no processo de planejamento em saúde dos municípios, a não integralização das contrapartidas na aplicação do mínimo pactuado para o financiamento do Componente básico da Assistência Farmacêutica nos municípios e a ausência de monitoramento e avaliação das ações de Assistência Farmacêutica no nível local. Espera-se que os resultados observados nesse estudo, possa contribuir para a melhoria da gestão da Assistência Farmacêutica visando a promoção do acesso aos medicamentos a população das regiões de saúde investigadas. 


\section{Referências}

1. Brasil. Presidência da República. Lei $n^{\circ}$ 8.080, de 19 de setembro de 1990. Dispõe sobre as condições para a promoção, proteção e recuperação da saúde, a organização e o funcionamento dos serviços correspondentes e dá outras providências. Brasília: Diário Oficial da União, 20 de setembro de 1990.

2. Oliveira LCF, et al. Assistência farmacêutica no Sistema Único de Saúde: da política nacional de medicamentos à atenção básica à saúde. Ciência e Saúde Coletiva, 2010; 15 (3): p 3561-7.

3. Brasil. Ministério da Saúde. Portaria MS no 204, de 29 de janeiro de 2007. Regulamenta o financiamento e a transferência dos recursos federais para as ações e os serviços de saúde, na forma de blocos de financiamento, com o respectivo monitoramento e controle. Brasília: Diário Oficial da União $n^{\circ} 22,31$ de janeiro de 2007, Seção I, página 45. [Retificação publicada no Diário Oficial da União nº 50, de 14/03/2007, Seção 1, página 46.].

4. Bruns SF, Luiza VL, Oliveira EA. Gestão da assistência farmacêutica em municípios do estado da Paraíba (PB): olhando a aplicação de recursos públicos. Rev. Adm. Pública, 2014; 48(3): p 745-765

5. Brasil. Ministério da Saúde. Secretaria de Ciência, Tecnologia e Insumos Estratégicos. Departamento de Assistência Farmacêutica e Insumos Estratégicos. Planejamento e implantação de serviços de cuidado farmacêutico na atenção básica à saude: a experiência de Curitiba (Cuidado farmacêutico na atenção básica; caderno 01). - 1. ed. rev. - Brasília, DF. 2015.

6. Brasil. Portaria $N^{o}$ GM/MS 1.555, de 30 de julho de 2013. Dispõe sobre as normas de financiamento e de execução do Componente Básico da Assistência Farmacêutica no âmbito do Sistema Único de Saúde. Brasília, DF, 2013.

7. Vieira FS. Qualificação dos serviços farmacêuticos no Brasil: aspectos inconclusos da agenda do Sistema Único de Saúde. Rev Panam Salud Publica. 2008; 24(2): p 91-100

8. Mendes SJ, Manzini F, Farias MR. Gestão da Assistência Farmacêutica: avaliação de um município catarinense. Revista Eletrônica Gestão \& Saúde, 2015; 01 (6): p 4-29

9. Brasil. Portaria $N^{o} 3.085$, de $1^{\circ}$ de dezembro de 2006. Regulamenta o Sistema de Planejamento do SUS. Disponível em: http://bibliotecaatualiza.com.br/cursos/portaria_3085.pdf. Acesso: 06 de dezembro de 2016. 
10. Vieira FS, Zucchi P. Gestão da Assistência Farmacêutica: análise da situação de alguns municípios. Tempus, actas de saúde colet, 2014; 8(4): p 11-29, dez.

11. Brasil. Lei No 8.666, de 21 de julho de 1993. Regulamenta o Art. 37, inciso XXI, da Constituição Federal, institui normas para licitações e contratos da Administração Pública e dá outras providências. Diário Oficial da União, Brasília, DF. 06 de julho de 1994.

12. Costa KS, Junior JMN. HÓRUS: inovação tecnológica na assistência farmacêutica no sistema único de saúde. Rev. Saúde Pública, 2012; 46 (1), p 91-99, Dez.

13. Marin N, Luzia VL, Osório-de-Castro CGS, Machado-dos-Santos S, organizadores. Assistência Farmacêutica para Gerentes Municipais. Rio de Janeiro: Organização PanAmericana da Saúde/Organização Mundial da Saúde, 2003.

14. Assunção IA, Santos K, Blatt CR. Relação municipal de medicamentos essenciais: semelhanças e diferenças. Rev Ciênc Farm Básica Apl, 2013; 34(3): p 431-9

15. Leite LO, Rezende DA. Modelo de gestão municipal baseado na utilização estratégica de recursos da tecnologia da informação para a gestão governamental: formatação do modelo e avaliação em um município. Rev. Adm. Publica, 2010; 44(2): p 459-93.

16. Bernardi CLB, Bieberbach EW, Thomé HI. Avaliação da assistência farmacêutica básica nos municípios de abrangência da $17 \mathrm{a}^{\mathrm{a}}$ Coordenadoria Regional de Saúde do Rio Grande do Sul. Rev Saúde e Sociedade, 2006; 15 (1), p 73-83.

Tabela 1 - Indicadores referentes a aquisição de medicamentos e financiamento da Assistência Farmacêutica, segundo responsável pela Assistência Farmacêutica municipal. QualisSUS Rede, 2015 $(\mathrm{n}=19)$.

\section{$\mathbf{N}$}

Participação do farmacêutico na elaboração do Termo de

Referência (TR) para a aquisição de medicamentos

Sim

Não

Não Sei

$\checkmark$ Existência de cronograma de envio das informações para programação da aquisição de medicamentos

Sim

Não

$\checkmark$ Conhecimento da Portaria do Ministério da Saúde, em vigência, a qual define as normas e execução do Financiamento do Componente Básico da Assistência Farmacêutica

Sim

Não

$\checkmark$ Conhecimento da Resolução da Comissão Intergestores 
Bipartite (CIB), em vigência, a qual define normas para a execução do Financiamento do Componente Básico da Assistência Farmacêutica no Estado

recurso total previsto, na Portaria em vigência do financiamento do Componente Básico da Assistência Farmacêutica, é suficiente para adquirir todos os itens de medicamentos padronizados nas quantidades adequadas?

Sim

Não

Não Sei

Destinação pelo município de recursos financeiros da contrapartida do Componente Básico da Assistência Farmacêutica no valor total previsto em portaria, no ano anterior

Sim

Não

Não Sei

$\checkmark$ Destinação pelo Estado de recursos financeiros da

contrapartida do Componente Básico da Assistência Farmacêutica no valor total previsto em portaria, no ano anterior

Sim

Não

Não Sei

$\checkmark$ Utilização dos recursos orçados para aquisição de medicamentos utilizados em sua totalidade, no ano anterior

Sim

Não

Não Sei

Existência de algum programa de co-financiamento da Assistência Farmacêutica instituído Sim

TABELA 2 - Indicadores referentes ao planejamento, segundo responsável pela Assistência Farmacêutica municipal. QualisSUS Rede, 2015

\section{INDICADORES}

$\mathbf{N}$

Participação do responsável pela Assistência Farmacêutica na elaboração do Plano Municipal de Saúde vigente

Sim

Não

Não Sei

$\checkmark$ Ações de Assistência Farmacêutica no último Relatório Anual de Gestão

Sim

Não

Não Sei

$\checkmark$ Recursos previstos e executados para a Assistência

Farmacêutica no último Relatório Anual de Gestão

Sim

Não

Não Sei

14

73,7

Previsão de recursos orçamentários na Lei Orçamentária 
Anual (LOA), em vigência, específicos para a aquisição de medicamentos

$\begin{array}{lcc}\text { Sim } & 05 & 26,3 \\ \text { Não } & 01 & 5,3 \\ \text { Não Sei } & 13 & 68,4 \\ \text { Previsão de recursos orçamentários na Lei Orçamentária } & \\ \text { Anual (LOA), em vigência, específicos para a estruturação } & \\ \text { da Assistência Farmacêutica } & & 10,5 \\ \text { Sim } & 02 & 5,3 \\ \text { Não } & 01 & 84,2 \\ \text { Não Sei } & 16 & \\ \text { Previsão de recursos orçamentários na Lei Orçamentária } & & \\ \text { Anual (LOA), em vigência, específicos para o } & & 5,3 \\ \text { desenvolvimento das ações da Assistência Farmacêutica, } & & 94,7 \\ \text { além do processo de aquisição e estruturação } & 01 & \\ \text { Sim Não } & 18 & 47,4 \\ \text { Não ḑões da Assistência Farmacêutica contempladas na } & & 52,6 \\ \text { Programação Anual da Saúde } & 09 & \end{array}$

TABELA 3 - Indicadores referentes a estruturais formais e sistema de informação da Assistência Farmacêutica, segundo responsável pela Assistência Farmacêutica municipal. QualisSUS Rede, 2015 $(\mathbf{n}=19)$.

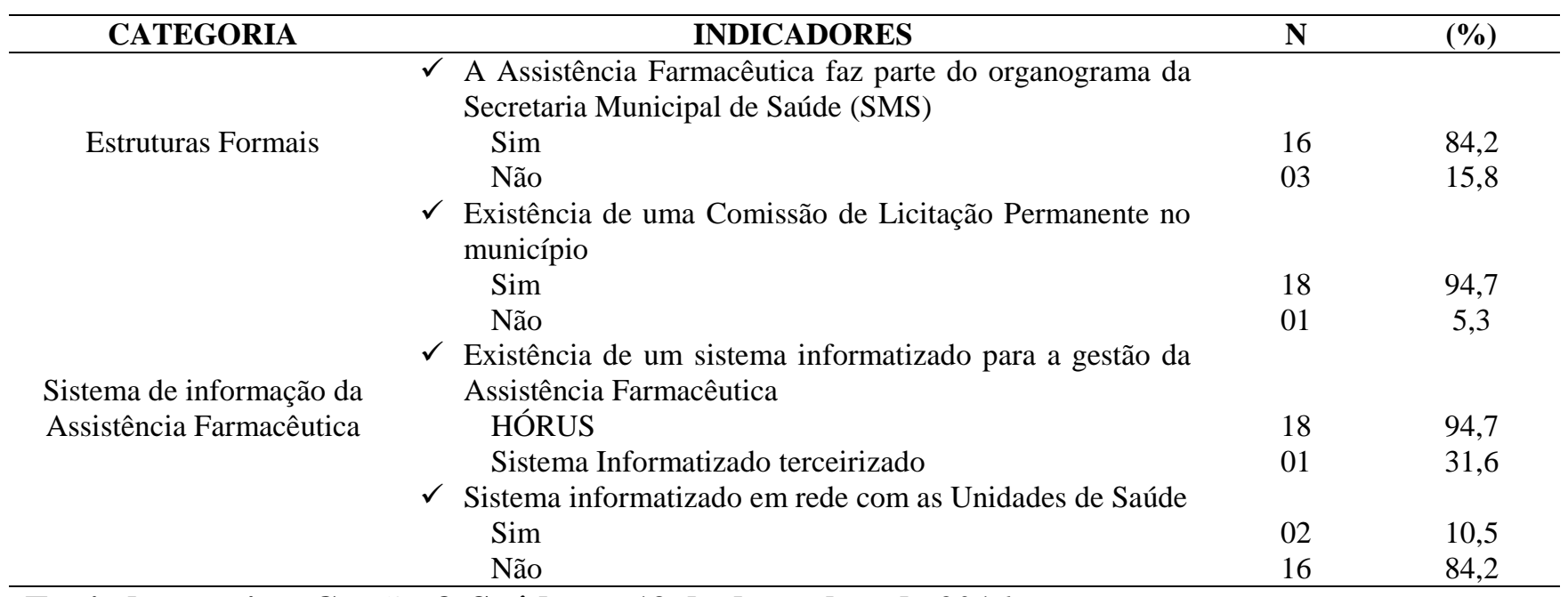

Enviado a revista Gestão \& Saúde em 19 de dezembro de 2016 


\section{CONCLUSÕES}

Fizemos uma identificação da situação dos serviços farmacêuticos técnicos gerenciais que envolvem a Assistência Farmacêutica na Região QualiSUS-Rede do Semiárido Cariri, no estado do Ceará. Observamos que alguns indicadores, principalmente os relacionados a categoria de aquisição e financiamento e o indicador da existência de um sistema informatizado para a gestão da Assistência Farmacêutica apresentaram bons resultados, mostrando resultados positivos nesses aspectos, ao passo que os indicadores da categoria planejamento apresentaram resultados mais preocupantes, mostrando que os responsáveis pela Assistência Farmacêutica nos municípios estudados devem se envolver mais no que se referi a aspectos dessa categoria. Esperamos que os resultados deste estudo tragam subsídios para a melhoria da gestão da Assistência Farmacêutica visando o desenvolvimento de ações para a qualificação da assistência farmacêutica dos municípios na perspectiva da integração regional. 


\section{CONSIDERAÇÕES FINAIS}

A Assistência Farmacêutica teve avanços consideráveis nos últimos anos, inclusive passando a fazer parte de muitos organogramas de estados e municípios. Outro aspecto que deve ser levado em consideração é que o montante financeiro envolvido nessa área de saúde pública é bem vultuoso, chegando a ser um dos maiores gastos em muitos estados e municípios.

Sugerimos uma maior participação dos responsáveis pela Assistência Farmacêutica nos aspectos relacionados a planejamento nas secretarias de saúde, pois os resultados observados nesse estudo, e em outros, mostram pouca participação desse profissional em decisões que envolvem essa categoria de indicadores. Sugerimos ainda que outros também analisem os dados da pesquisa QualiSUS-Rede inclusive para compararmos com os dados observados na Região QualiSUS-Rede do Semiárido Cariri, e dessa forma termos informações mais completas da Assistência Farmacêutica no Brasil, tendo em vista que várias regiões, de várias partes e com várias realidades foram pesquisadas e assim possamos construir uma Assistência Farmacêutica cada vez mais forte e que atenda às necessidades da população brasileira.

Com relação a demais instâncias envolvidas com Assistência Farmacêutica, como Ministério da Saúde e CONASEMS, propomos um acompanhamento dos municípios, no que se refere ao tema. Dessa forma acreditamos conseguir uma melhor qualificação dos municípios e também dos estados.

Para essa qualificação, com apoio institucional, sugerimos um suporte mais específico no que se refere as ações dessas instâncias junto a estados e municípios com a realização de oficinas que envolvam o tema Assistência Farmacêutica. 


\section{REFERÊNCIAS BIBLIOGRÁFICAS}

1. BRASIL. Presidência da República. Lei no 8.080, de 19 de setembro de 1990. Dispõe sobre as condições para a promoção, proteção e recuperação da saúde, a organização e o funcionamento dos serviços correspondentes e dá outras providências. Brasília: Diário Oficial da União, 20 de setembro de 1990.

2. Oliveira LCF, et al. Assistência farmacêutica no Sistema Único de Saúde: da política nacional de medicamentos à atenção básica à saúde. Ciência e Saúde Coletiva, 2010; 15 (3): p 3561-7.

3. BRASIL. Ministério da Saúde. Portaria MS no 204, de 29 de janeiro de 2007. Regulamenta o financiamento e a transferência dos recursos federais para as ações e os serviços de saúde, na forma de blocos de financiamento, com o respectivo monitoramento e controle. Brasília: Diário Oficial da União nº 22, 31 de janeiro de 2007, Seção I, página 45. [Retificação publicada no Diário Oficial da União no 50, de 14/03/2007, Seção 1, página 46.].

4. Bruns SF, Luiza VL, Oliveira EA. Gestão da assistência farmacêutica em municípios do estado da Paraíba (PB): olhando a aplicação de recursos públicos. Rev. Adm. Pública, 2014; 48(3): p 745-765

5. BRASIL. Ministério da Saúde. Secretaria de Ciência, Tecnologia e Insumos Estratégicos. Departamento de Assistência Farmacêutica e Insumos Estratégicos. Planejamento e implantação de serviços de cuidado farmacêutico na atenção básica à saude: a experiência de Curitiba (Cuidado farmacêutico na atenção básica; caderno 01). - 1. ed. rev. - Brasília, DF. 2015.

6. Oliveira MA, Bermudez JAZ, Osorio-de-castro CGS. Assistência Farmacêutica e acesso a medicamentos. Rio de Janeiro: Editora Fiocruz, 2007.

7. Bermudez JAZ, Luiza LV. Assistência Farmacêutica. In: Giovanella L, Lobato LVC, Noronha JC, Carvalho AI. Políticas e Sistema de Saúde no Brasil. 2a Edição revista e ampliada. Rio de Janeiro: Editora Fiocruz, 2012.

8. BRASIL. Portaria No 3.916, de 30 de outubro de 1998. Aprova a Política Nacional de Medicamentos e dá outras providências. Diário Oficial da União, Poder Executivo, Brasília, DF. 30 de outubro de 1998.

9. Marin N, Luzia VL, Osório-de-Castro CGS, Machado-dos-Santos S, organizadores. Assistência Farmacêutica para Gerentes Municipais. Rio de Janeiro: Organização PanAmericana da Saúde/Organização Mundial da Saúde, 2003. 
10. BRASIL. Resolução $N^{\circ}$ 338, de 06 de maio de 2004. Aprova a Política Nacional de Assistência Farmacêutica. Diário Oficial da União, Poder Executivo, Brasília, DF. 06 de maio de 2004.

11. BRASIL. Portaria $\mathrm{N}^{\circ}$ GM/MS 1.555, de 30 de julho de 2013. Dispõe sobre as normas de financiamento e de execução do Componente Básico da Assistência Farmacêutica no âmbito do Sistema Único de Saúde. Brasília, DF, 2013. Disponível em:

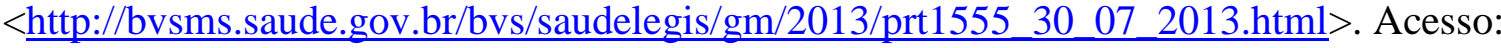
09 de outubro 2016.

12. BRASIL. Portaria $N^{o} 1.214$, de 13 de junho de 2012. Institui o Programa Nacional de Qualificação da Assistência Farmacêutica no âmbito do Sistema Único de Saúde (QUALIFAR-SUS). Diário Oficial da União, Brasília, DF. 14 de junho de 2012.

13. BRASIL. Lei $\mathrm{N}^{\circ}$ 8.666, de 21 de julho de 1993. Regulamenta o Art. 37, inciso XXI, da Constituição Federal, institui normas para licitações e contratos da Administração Pública e dá outras providências. Diário Oficial da União, Brasília, DF. 06 de julho de 1994.

14. Paim JS, Teixeira CF. Política, Planejamento e gestão em Saúde: balanço do estado da arte. Rev. Saude Publica 2006; 40(N Esp):73-78.

15. Rivera FJU, Artmann E. Planejamento e gestão em saúde: histórico e tendências com base numa visão comunicativa. Ciência e Saúde Coletiva, 2010; 15 (5): p 2265-74.

16. Mintzberg H. Ascensão e queda do planejamento estratégico. Porto Alegre: Bookman; 2004.

17. Mendes SJ, Manzini F, Farias MR. Gestão da Assistência Farmacêutica: avaliação de um município catarinense. Revista Eletrônica Gestão \& Saúde, 2015; 01 (6): p 4-29.

18. Branco MAF. Sistemas de informação em saúde no nível local. Cad. Saúde Pública, 1996; 12(2): p 267-70.

19. Branco MA. Informação e saúde: uma ciência e suas políticas em uma nova era. Rio de Janeiro: Editora Fiocruz, 2006.

20. Mendes EV. As redes de atenção à saúde. Ciência \& Saúde Coletiva, 2010; 15(5): p 2297-2305.

21. Costa KS, Junior JMN. HÓRUS: inovação tecnológica na assistência farmacêutica no sistema único de saúde. Rev. Saúde Pública, 2012; 46 (1), p 91-99, Dez.

22. BRASIL. Portaria $N^{\circ} 4.279$, de 30 de dezembro de 2010. Estabelece diretrizes para a Organização da Rede de Atenção à Saúde no Âmbito do Sistema Único de Saúde. Diário Oficial da União, Poder Executivo, Brasília, DF. 31 de dezembro de 2010. 
23. BRASIL. Ministério da Saúde. Secretaria Executiva. Departamento de Economia da Saúde, Investimentos e Desenvolvimento. Projeto de Formação e Melhoria da Qualidade da Rede de Saúde - QualiSUS-Rede - MANUAL OPERACIONAL, Volume 1 Documento-Base, 2011.

24. BRASIL. Ministério da Saúde. Secretaria Executiva. Departamento de Economia da Saúde, Investimentos e Desenvolvimento. MANUAL OPERACIONAL, Volume 2 Adesão ao Projeto e Formulação das Propostas dos Subprojetos. Brasília-DF, Janeiro de 2012. 
ANEXOS

PARECER DA COMISSÃO NACIONAL DE ÉTICA EM PESQUISA

\section{COMISSÃO NACIONAL DE ÉTICA EM PESQUISA}

\section{PARECER CONSUBSTANCIADO DA CONEP}

\section{DADOS DO PROJETO DE PESQUISA}

Titulo da Pesquisa: A ASSISTÊNCIA FARMACÊUTICA NAS REDES DE ATENÇÄO Ȧ SAÚDE: UM RECORTE NAS REGIŐES DO PROJETO QUALISUS-REDE

Pesquisador: KAREN SARMENTO COSTA

Área Temática:

Versäo: 3

CAAE: 19554413.6 .0000 .0008

Instituiçăo Proponente: Secretaria de Ciência e Tecnologia e Insumos Estratégicos

Patrocinador Principal: Ministério da Saúde

$$
\text { The Worl Bank }
$$

\section{DADOS DO PARECER}

Número do Parecer: 399.423

Data da Relatoria: 18/09/2013

Situaçăo do Parecer:

Aprovado

Consideraçöes Finais a critério da CONEP:

Diante do exposto, a Comissăo Nacional de Ética em Pesquisa - CONEP, de acordo com as atribuiçőes definidas na Resolução CNS 466/2012, manifesta-se pela aprovaçăo do projeto de pesquisa proposto.

Situaçăo: Protocolo aprovado.

Endereço: SEPN 510 NORTE, BLOCO A $1^{\circ}$ SUBSOLO, Edificio EX-INAN - Unidade II - Ministério da Saúde Bairro: Asa Norte CEP: $70.750-521$

$\begin{array}{lr}\text { UF: DF } & \text { Munic } \\ \text { Telefone: } & \text { (61)3315-5878 }\end{array}$ E-mail: conep@saude.gov.br 
INSTRUMENTO DE COLETA DE DADOS

Perfil 2: Responsável pela Assistência Farmacêutica

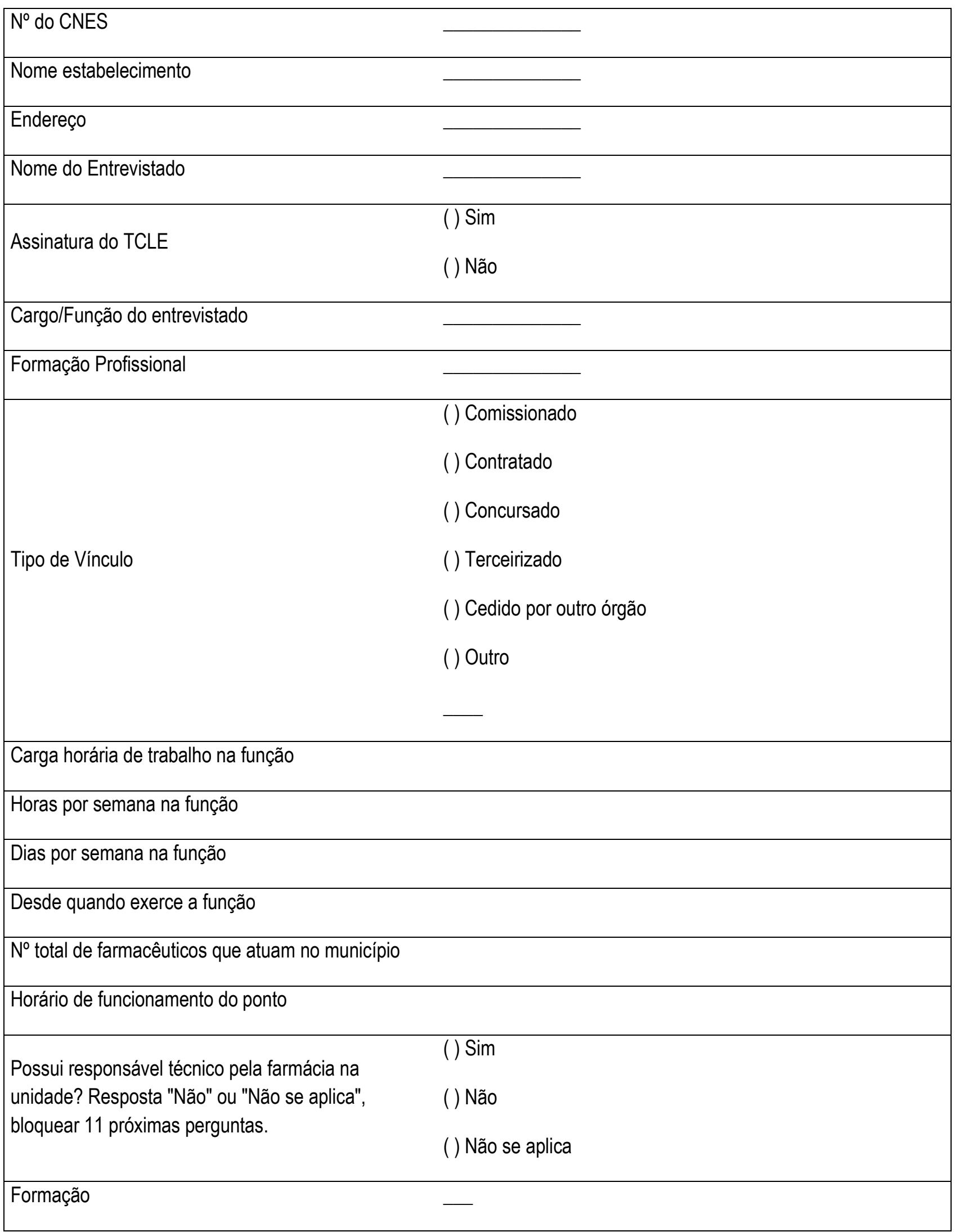




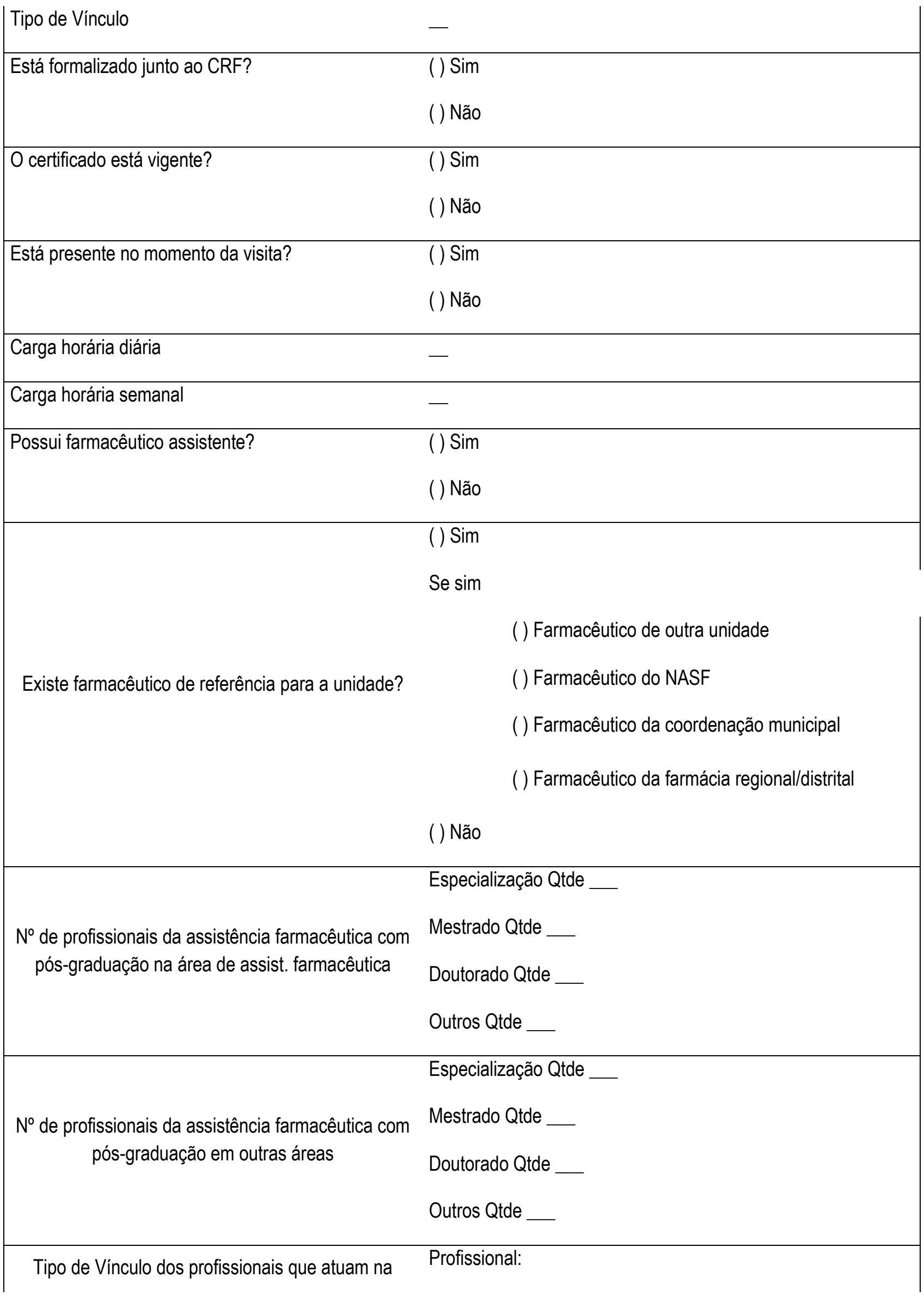


assistência farmacêutica por categoria profissional

( ) Farmacêutico

( ) Aux/Técn de farmácia

( ) Aux/Técn de enfermagem

( ) Aux. Administrativo

( ) Demais profissionais de nível superior

Tipo de Vínculo

( ) Comissionado

( ) Concursado

( ) Contratado

( ) Cedido por outro órgão

( ) Terceirizado

( ) Estagiário

Quantidade

Observação

Profissional:

( ) Farmacêutico

( ) Aux/Técn de farmácia

( ) Aux/Técn de enfermagem

( ) Aux. Administrativo

( ) Demais profissionais de nível superior

Tipo de Vínculo

( ) Comissionado

( ) Concursado

( ) Contratado

( ) Cedido por outro órgão

( ) Terceirizado

() Estagiário 
Quantidade

Observação

Profissional:

( ) Farmacêutico

( ) Aux/Técn de farmácia

( ) Aux/Técn de enfermagem

( ) Aux. Administrativo

( ) Demais profissionais de nível superior

Tipo de Vínculo

( ) Comissionado

( ) Concursado

( ) Contratado

( ) Cedido por outro órgão

( ) Terceirizado

( ) Estagiário

Quantidade

Observação

Profissional:

( ) Farmacêutico

() Aux/Técn de farmácia

( ) Aux/Técn de enfermagem

( ) Aux. Administrativo

( ) Demais profissionais de nível superior

Tipo de Vínculo
( ) Comissionado
( ) Concursado 
( ) Contratado

( ) Cedido por outro órgão

( ) Terceirizado

( ) Estagiário

Quantidade

Observação

Profissional:

( ) Farmacêutico

( ) Aux/Técn de farmácia

( ) Aux/Técn de enfermagem

( ) Aux. Administrativo

( ) Demais profissionais de nível superior

Tipo de Vínculo

( ) Comissionado

( ) Concursado

() Contratado

( ) Cedido por outro órgão

( ) Terceirizado

() Estagiário

Quantidade

Observação

D4P01 - Tem conhecimento da Portaria do Ministério ( ) Sim da Saúde, em vigência, a qual define as normas e execução do Financiamento do Componente Básico da Assistência Farmacêutica?

( ) Não

D4P02 - Tem conhecimento da Resolução da ( ) $\operatorname{Sim}$

Comissão Intergestores Bipartite (CIB), em vigência, 


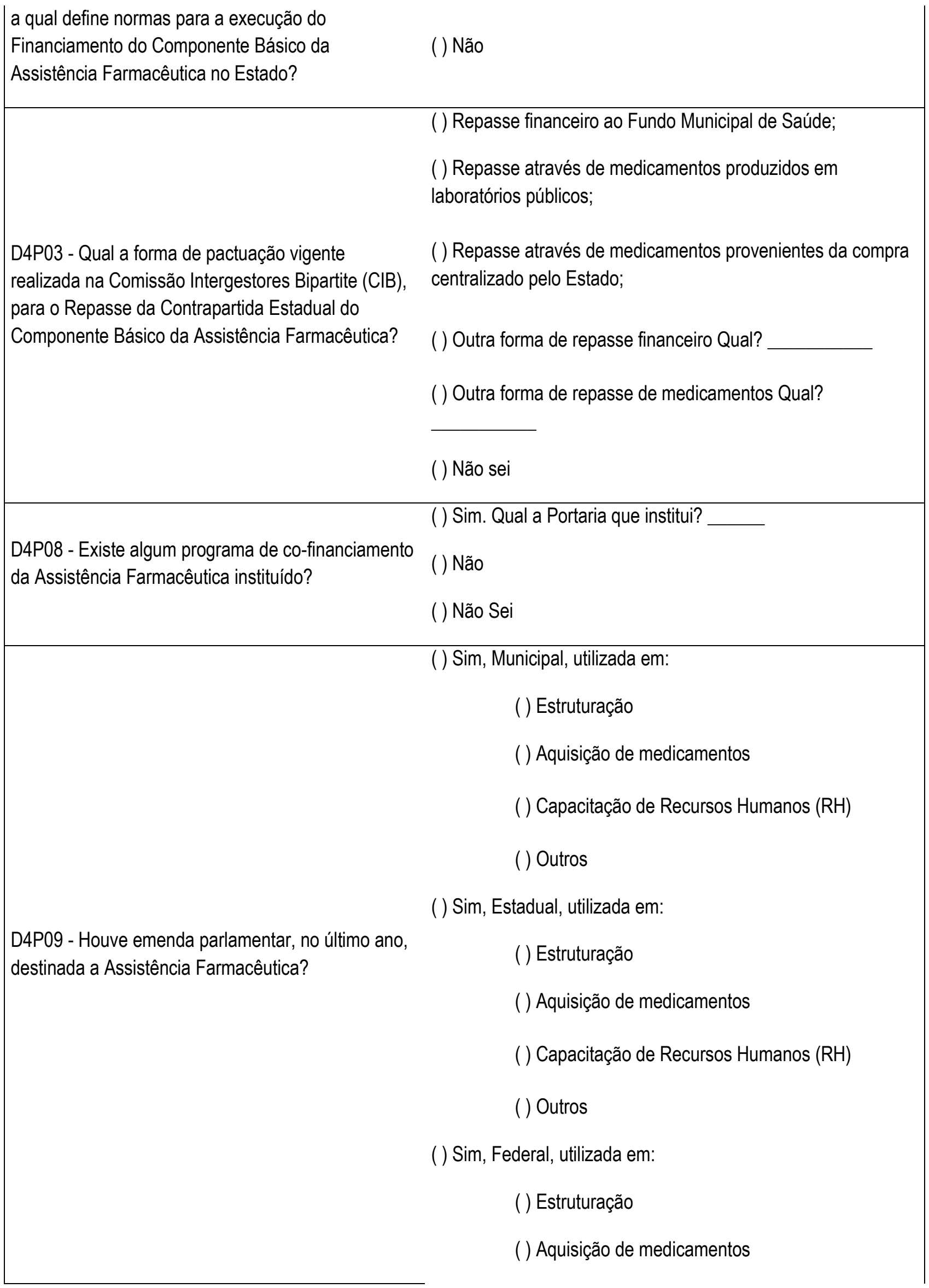




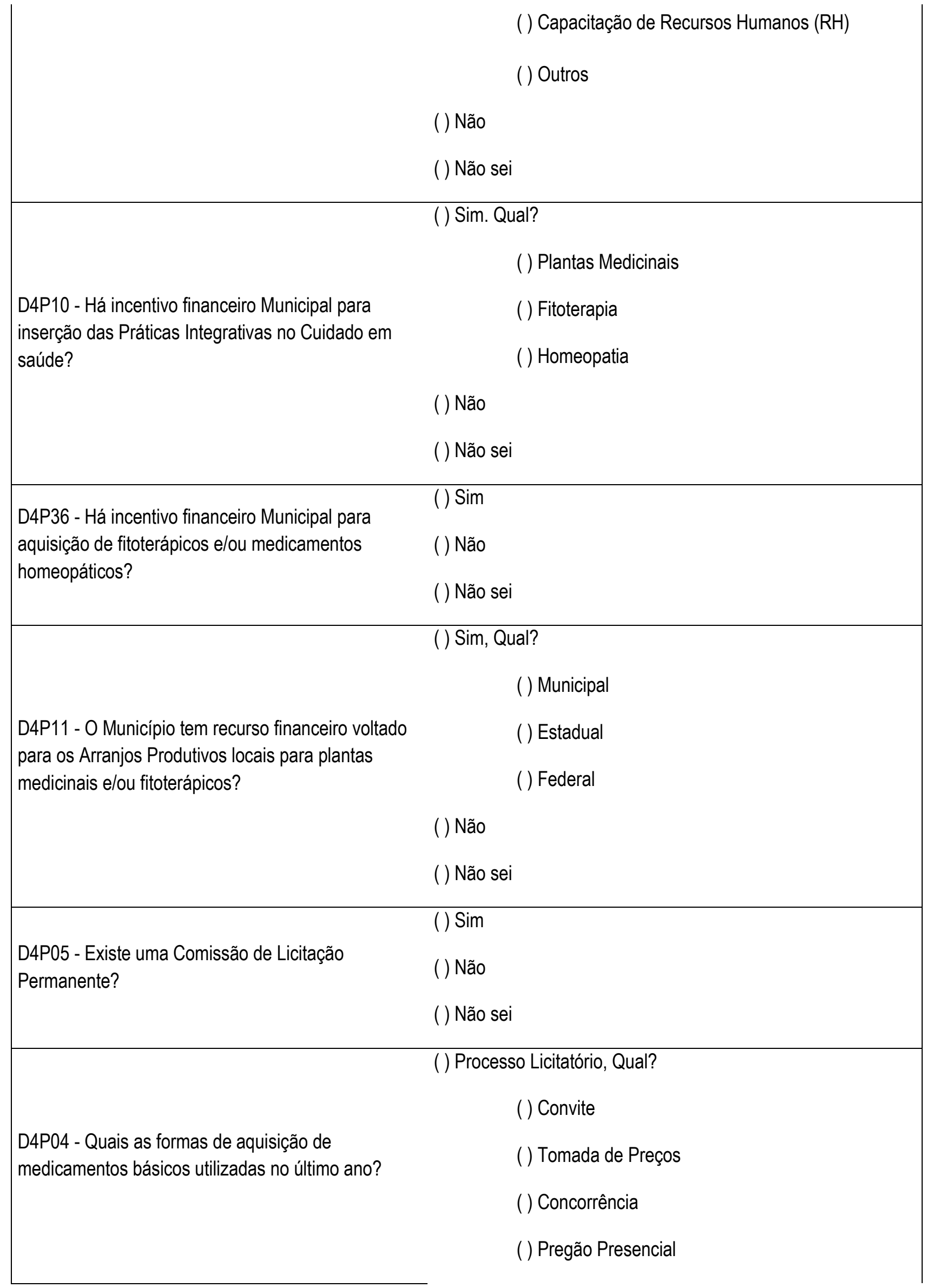




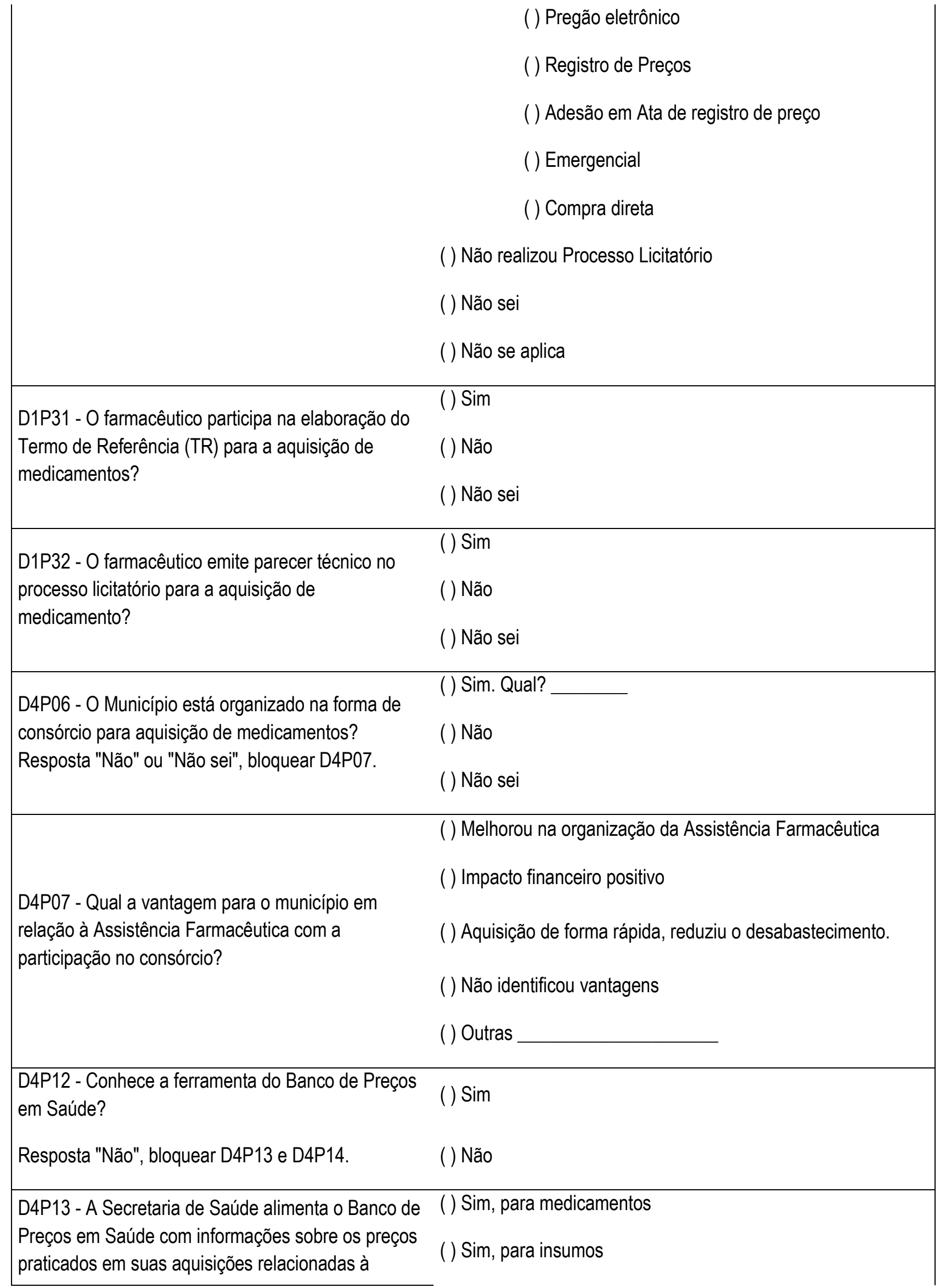




\begin{tabular}{|c|c|}
\hline Assistência Farmacêutica? & $\begin{array}{l}\text { ( ) Não } \\
\text { ( ) Não sei }\end{array}$ \\
\hline $\begin{array}{l}\text { D4P14 - A Secretaria de Saúde utiliza as } \\
\text { informações disponíveis no Banco de Preços para } \\
\text { orientar o processo de aquisição de medicamentos? }\end{array}$ & $\begin{array}{l}\text { ( ) Sim, para medicamentos } \\
\text { ( ) Sim, para insumos } \\
\text { ( ) Não } \\
\text { ( ) Não sei }\end{array}$ \\
\hline $\begin{array}{l}\text { D1P05 - O responsável pela Asssitência } \\
\text { Farmacêutica participa da elaboração do Plano } \\
\text { Municipal de Saúde? }\end{array}$ & $\begin{array}{l}\text { ( ) Sim } \\
\text { ( ) Não } \\
\text { ( ) Não sei }\end{array}$ \\
\hline $\begin{array}{l}\text { D1P6 - O responsável pela Assitência Farmacêutica } \\
\text { participou na elaboração do Plano Municipal de } \\
\text { Saúde atual e/ou de suas atualizações? }\end{array}$ & $\begin{array}{l}\text { ( ) Sim } \\
\text { ( ) Não } \\
\text { ( ) Não sei }\end{array}$ \\
\hline $\begin{array}{l}\text { D4P19 - O Responsável pela Assistência } \\
\text { farmacêutica participou da elaboração da Lei de } \\
\text { Diretrizes Orçamentárias (LDO), em vigência? }\end{array}$ & $\begin{array}{l}\text { ( ) Sim } \\
\text { ( ) Não } \\
\text { ( ) Não sei }\end{array}$ \\
\hline $\begin{array}{l}\text { D4P20 - O responsável pela Assistência } \\
\text { Farmacêutica tem conhecimento da Lei } \\
\text { Orçamentária Anual (LOA), em vigência? }\end{array}$ & $\begin{array}{l}\text { ( ) Sim } \\
\text { ( ) Não } \\
\text { ( ) Não sei }\end{array}$ \\
\hline $\begin{array}{l}\text { D4P21 - O responsável pela Assistência } \\
\text { Farmacêutica participou na elaboração da Lei } \\
\text { Orçamentária Anual (LOA), em vigência? }\end{array}$ & $\begin{array}{l}\text { ( ) Sim } \\
\text { ( ) Não } \\
\text { ( ) Não sei }\end{array}$ \\
\hline $\begin{array}{l}\text { D4P22 - Na Lei Orçamentária Anual (LOA), em } \\
\text { vigência, está previsto recursos orçamentários } \\
\text { específicos para a aquisição de medicamentos? }\end{array}$ & $\begin{array}{l}\text { ( ) Sim } \\
\text { ( ) Não } \\
\text { ( ) Não sei }\end{array}$ \\
\hline $\begin{array}{l}\text { D4P23 - Na Lei Orçamentária Anual (LOA), em } \\
\text { vigência, está previsto recursos orçamentários } \\
\text { específicos para a estruturação da Assistência } \\
\text { Farmacêutica? }\end{array}$ & $\begin{array}{l}\text { ( ) Sim } \\
\text { ( ) Não } \\
\text { ( ) Não sei }\end{array}$ \\
\hline
\end{tabular}




\begin{tabular}{|c|c|}
\hline $\begin{array}{l}\text { D4P24 - Na Lei Orçamentária Anual (LOA), em } \\
\text { vigência, está previsto recursos orçamentários } \\
\text { específicos para o desenvolvimento das ações da } \\
\text { Assistência Farmacêutica, além do processo de } \\
\text { aquisição e estruturação? }\end{array}$ & $\begin{array}{l}\text { ( ) Sim, Qual? } \\
\text { ( ) Não } \\
\text { ( ) Não sei }\end{array}$ \\
\hline $\begin{array}{l}\text { D4P18 - O Responsável pela Assistência } \\
\text { Farmacêutica participou da elaboração do Plano } \\
\text { Plurianual? }\end{array}$ & $\begin{array}{l}\text { ( ) Sim } \\
\text { ( ) Não } \\
\text { ( ) Não sei }\end{array}$ \\
\hline $\begin{array}{l}\text { D4P25 - O Responsável pela Assistência } \\
\text { Farmacêutica participou na elaboração da } \\
\text { Programação Anual da Saúde? }\end{array}$ & $\begin{array}{l}\text { ( ) Sim } \\
\text { ( ) Não } \\
\text { ( ) Não sei }\end{array}$ \\
\hline $\begin{array}{l}\text { D4P26 - As ações da Assistência Farmacêutica } \\
\text { estão contempladas na Programação Anual da } \\
\text { Saúde? Resposta "Não" ou "Não sei", bloquear } \\
\text { D4P27 }\end{array}$ & $\begin{array}{l}\text { ( ) Sim } \\
\text { ( ) Não } \\
\text { ( ) Não sei }\end{array}$ \\
\hline $\begin{array}{l}\text { D4P27 - Na Programação Anual da Saúde, em } \\
\text { vigência, estão previstas ações da Assistência } \\
\text { Farmacêutica voltadas para: }\end{array}$ & $\begin{array}{l}\text { ( ) Capacitações/Educação Permanente } \\
\text { () Informatização } \\
\text { ( ) Ampliação de Recursos Humanos } \\
\text { () Reformas } \\
\text { () Construção } \\
\text { () Outras: } \\
\text { () Não sei }\end{array}$ \\
\hline $\begin{array}{l}\text { D4P15 - O responsável pela Assistência } \\
\text { Farmacêutica participa da elaboração do Relatório } \\
\text { Anual de Gestão (RAG)? }\end{array}$ & $\begin{array}{l}\text { ( ) Sim } \\
\text { ( ) Não } \\
\text { ( ) Não sei }\end{array}$ \\
\hline $\begin{array}{l}\text { D4P16 - As ações de Assistência Farmacêutica } \\
\text { foram descritas no último Relatório Anual de Gestão? }\end{array}$ & $\begin{array}{l}\text { ( ) Sim } \\
\text { ( ) Não } \\
\text { ( ) Não sei }\end{array}$ \\
\hline D4P17 - Os Recursos previstos e executados para a & ( ) $\operatorname{Sim}$ \\
\hline
\end{tabular}




\begin{tabular}{|c|c|}
\hline $\begin{array}{l}\text { Assistência Farmacêutica foram descritas no último } \\
\text { Relatório Anual de Gestão? }\end{array}$ & $\begin{array}{l}\text { ( ) Não } \\
\text { ( ) Não sei }\end{array}$ \\
\hline $\begin{array}{l}\text { D4P31 - O Município destinou recursos financeiros } \\
\text { da contrapartida do Componente Básico da } \\
\text { Assistência Farmacêutica no valor total previsto em } \\
\text { portaria, no ano anterior? }\end{array}$ & $\begin{array}{l}\text { ( ) Sim } \\
\text { ( ) Não } \\
\text { ( ) Não sei } \\
\text { ( ) Não se aplica (para estado) }\end{array}$ \\
\hline $\begin{array}{l}\text { D4P32 - O Estado destinou recursos financeiros da } \\
\text { contrapartida do Componente Básico da Assistência } \\
\text { Farmacêutica no valor total previsto em portaria, no } \\
\text { ano anterior? }\end{array}$ & $\begin{array}{l}\text { ( ) Sim } \\
\text { ( ) Não } \\
\text { ( ) Não sei }\end{array}$ \\
\hline $\begin{array}{l}\text { D4P33 - Nos últimos seis meses, o Município } \\
\text { destinou recursos financeiros da contrapartida do } \\
\text { Componente Básico da Assistência Farmacêutica } \\
\text { previsto em portaria? }\end{array}$ & $\begin{array}{l}\text { ( ) Sim } \\
\text { ( ) Não } \\
\text { ( ) Não sei } \\
\text { ( ) Não se aplica (para estado) }\end{array}$ \\
\hline $\begin{array}{l}\text { D4P34 - Nos últimos seis meses, o Estado destinou } \\
\text { recursos financeiros da contrapartida do } \\
\text { Componente Básico da Assistência Farmacêutica } \\
\text { previsto em portaria? }\end{array}$ & $\begin{array}{l}\text { ( ) Sim } \\
\text { ( ) Não } \\
\text { ( ) Não sei }\end{array}$ \\
\hline $\begin{array}{l}\text { D4P35 - Os recursos orçados para aquisição de } \\
\text { medicamentos foram utilizados em sua totalidade, no } \\
\text { ano anterior? }\end{array}$ & $\begin{array}{l}\text { ( ) Sim } \\
\text { ( ) Não } \\
\text { ( ) Não sei }\end{array}$ \\
\hline $\begin{array}{l}\text { D4P30 - O recurso total previsto, na Portaria em } \\
\text { vigência do financiamento do Componente Básico da } \\
\text { Assistência Farmacêutica, é suficiente para adquirir } \\
\text { todos os itens de medicamentos padronizados nas } \\
\text { quantidades adequadas? }\end{array}$ & $\begin{array}{l}\text { ( ) Sim } \\
\text { ( ) Não } \\
\text { ( ) Não sei }\end{array}$ \\
\hline $\begin{array}{l}\text { D1P22 - Existe demanda judicial para fornecimento } \\
\text { de medicamento? } \\
\text { Resposta "Não" e "Não sei", bloquear D1P23, D1P24 } \\
\text { e D1P25. }\end{array}$ & $\begin{array}{l}\text { ( ) Sim } \\
\text { ( ) Não } \\
\text { ( ) Não sei }\end{array}$ \\
\hline D1P23 - O gestor municipal conta com assessoria & () $\mathrm{Sim}$ \\
\hline
\end{tabular}




\begin{tabular}{|c|c|}
\hline $\begin{array}{l}\text { jurídica para resposta às demandas judiciais para } \\
\text { fornecimento de medicamentos? }\end{array}$ & $\begin{array}{l}\text { ( ) Não } \\
\text { ( ) Não sei }\end{array}$ \\
\hline $\begin{array}{l}\text { D1P24 - O gestor Municipal conta com assessoria } \\
\text { técnica farmacêutica para resposta às demandas } \\
\text { judiciais para fornecimento de medicamentos? }\end{array}$ & $\begin{array}{l}\text { ( ) Sim } \\
\text { ( ) Não } \\
\text { ( ) Não sei }\end{array}$ \\
\hline $\begin{array}{l}\text { D1P25 - Qual a maior incidência de demanda } \\
\text { judicial? }\end{array}$ & $\begin{array}{l}\text { ( ) Componente Básico } \\
\text { ( ) Componente Especializado } \\
\text { ( ) Componente Estratégico } \\
\text { ( ) Oncologia } \\
\text { ( ) Insulina análoga } \\
\text { ( ) Outros }\end{array}$ \\
\hline $\begin{array}{l}\text { D1P07 - O Conselho Municipal de Saúde participa } \\
\text { nas decisões sobre questões relacionadas à } \\
\text { Assistência Farmacêutica no município? }\end{array}$ & $\begin{array}{l}\text { ( ) Sim } \\
\text { ( ) Não } \\
\text { ( ) Não sei }\end{array}$ \\
\hline $\begin{array}{l}\text { D1P08 - A Prestação de Contas dos investimentos } \\
\text { em Assistência Farmacêutica foi apresentada ao } \\
\text { Conselho Municipal de Saúde, no último ano? }\end{array}$ & $\begin{array}{l}\text { ( ) Sim } \\
\text { ( ) Não } \\
\text { ( ) Não sei }\end{array}$ \\
\hline $\begin{array}{l}\text { D1P9 - Existe }(\mathrm{m}) \text { mecanismo(s) no Município para } \\
\text { receber críticas e sugestões dos usuários sobre a } \\
\text { Assistência Farmacêutica? }\end{array}$ & $\begin{array}{l}\text { ( ) Sim. Ouvidoria. } \\
\text { ( ) Sim. Outros: } \\
\text { ( ) Não } \\
\text { ( ) Não sei }\end{array}$ \\
\hline $\begin{array}{l}\text { D1P10 - Você recebeu críticas e/ou sugestões sobre } \\
\text { a Assistência Farmacêutica, no último ano? }\end{array}$ & $\begin{array}{l}\text { ( ) Sim, críticas } \\
\text { ( ) Sim, sugestões } \\
\text { ( ) Sim, elogios } \\
\text { ( ) Sim, denuncias } \\
\text { ( ) Não } \\
\text { ( ) Não sei }\end{array}$ \\
\hline
\end{tabular}


D1P01 - A Assistência Farmacêutica faz parte do organograma da Secretaria Municipal de Saúde (SMS)?
( ) Sim. Qual terminologia?

( ) Não

( ) Não sei
D1P2 - No caso de existir uma coordenação de Assistência Farmacêutica Municipal, essa é coordenada por farmacêutico(a)?

\section{( ) Sim}

( ) Não. Qual a formação do coordenador da Assistência Farmacêutica?

( ) Não se aplica de pessoal da Assistência Farmacêutica? Resposta:

( ) Seleção

( ) Programação

( ) Produção

( ) Aquisição

D3P16 - Quais atividades Técnico-gerenciais o(s) farmacêutico(s) realiza(m)?

() Recebimento

( ) Armazenamento

( ) Distribuição

( ) Outros:

( ) Não se aplica.

( ) Dispensação

( ) Matriciamento

( ) Grupo Operativo de Educação em Saúde

( ) Participação em construção de Projeto Terapêutico Singular

D3P16.1 - Quais atividades Técnico-assistenciais $\mathrm{o}(\mathrm{s})$ farmacêutico(s) realiza $(\mathrm{m})$ ?

( ) Discussão de Casos

() Seguimento Farmacoterapêutico

( ) Orientação em Saúde

() Outros:

( ) Não se aplica 
( ) Sim. Quantos?

D3P14 - Existe farmacêutico na equipe do Núcleo de

Apoio a Saúde da Família - NASF?

( ) Não

Resposta "Não", "Não sei" e "Não se aplica", bloquear D3P15 e D3P15_1

( ) Não sei

( ) Não se aplica

( ) Seleção

( ) Programação

( ) Produção

D3P15 - Quais atividades técnico-gerenciais o(s)

( ) Aquisição

farmacêutico(s) do Núcleo de Apoio a Saúde da

() Recebimento

Família - NASF realizam?

( ) Armazenamento

( ) Distribuição

( ) Outros:

( ) Não se aplica.

( ) Dispensação

( ) Matriciamento

( ) Grupo Operativo de Educação em Saúde

D3P15.1 - Quais atividades técnico-assistenciais o(s)

farmacêutico(s) do Núcleo de Apoio a Saúde da

Família - NASF realizam?

( ) Discussão de Casos

( ) Seguimento Farmacoterapêutico

( ) Orientação em Saúde

() Outros:

( ) Não se aplica.

( ) Sim

D3P13 - O farmacêutico realiza Visitas Domiciliares? () Não

( ) Não sei

D1P41 - Existe um plano de cargos e salários que

( ) $\operatorname{Sim}$ 


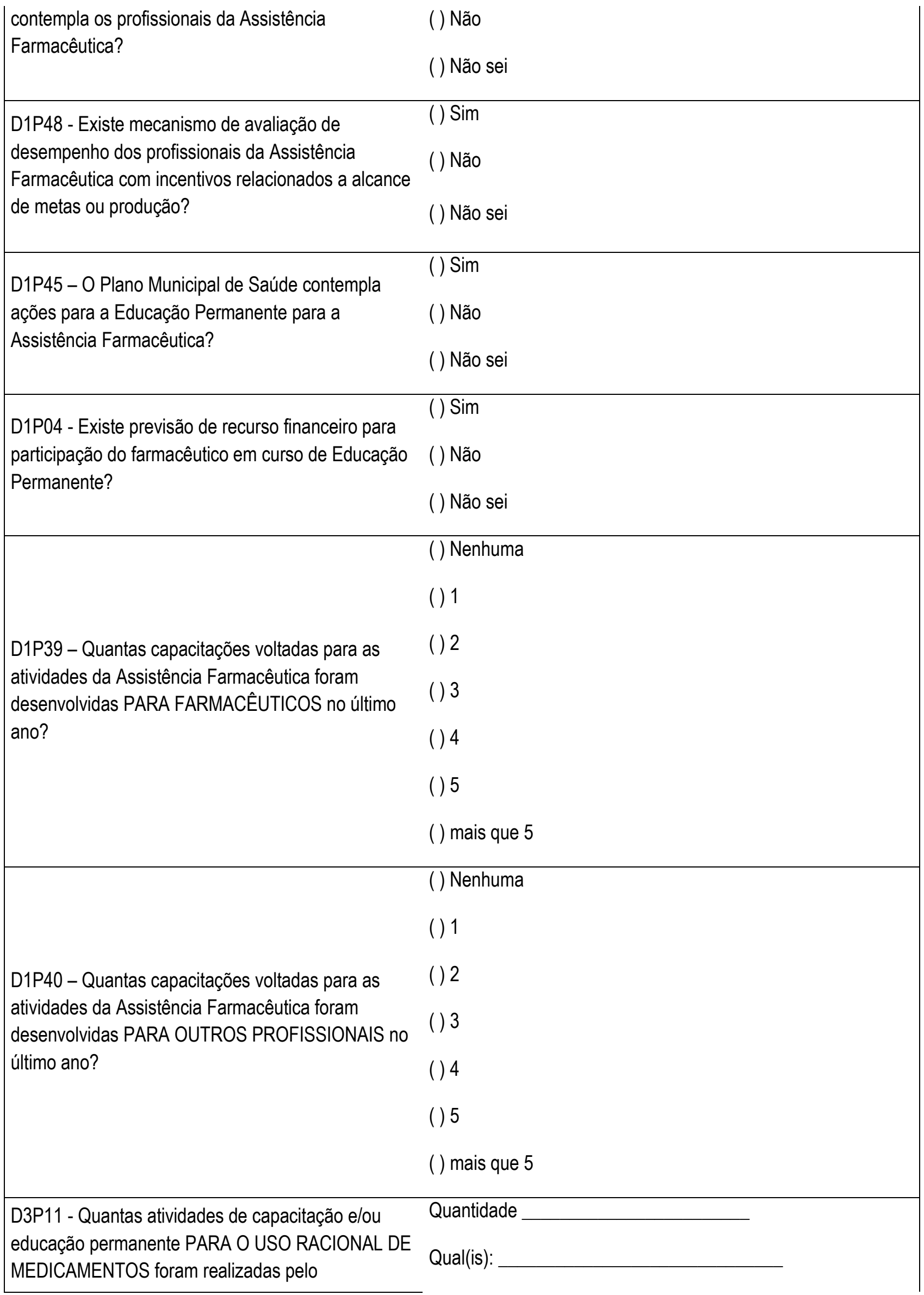




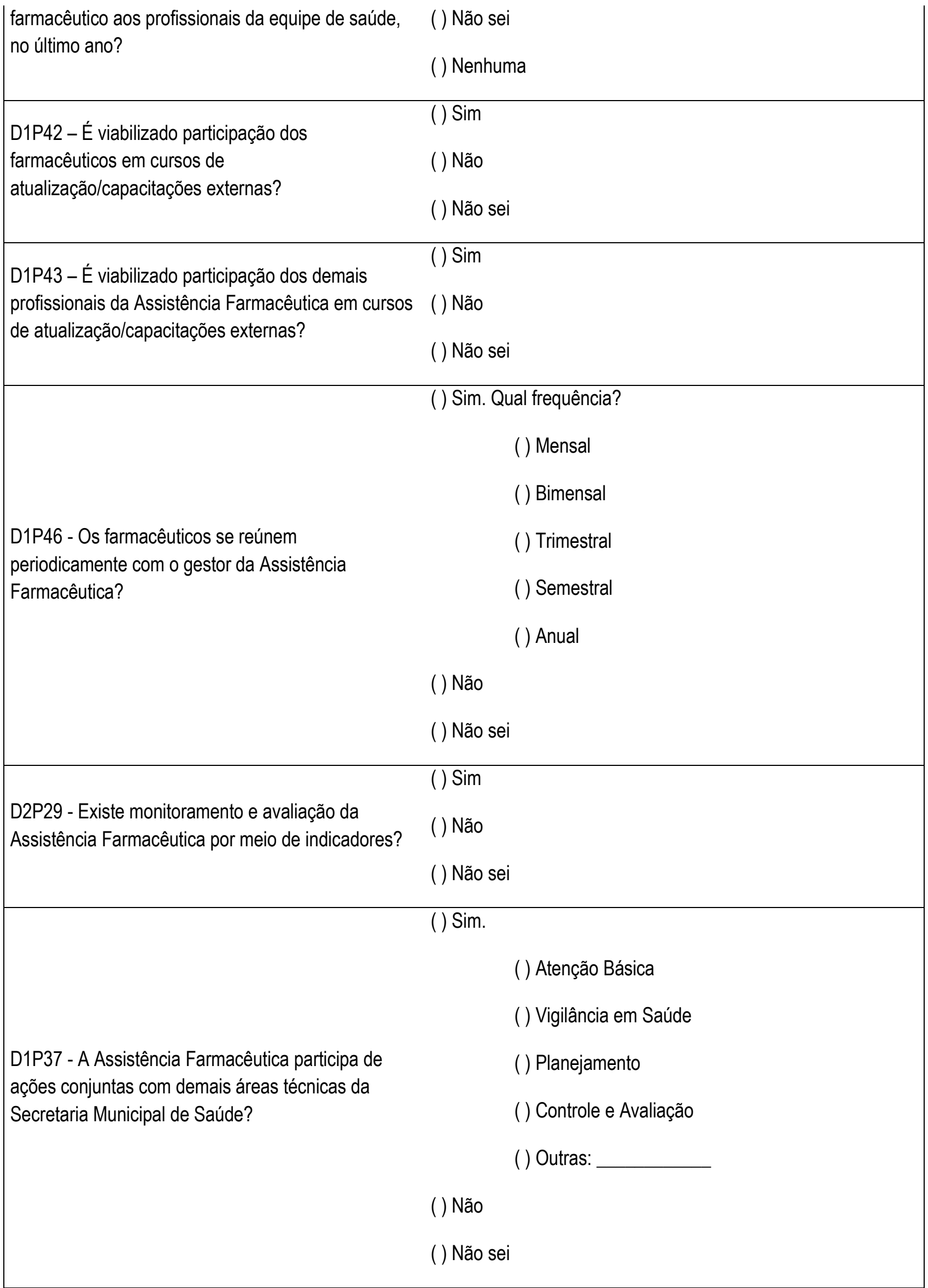




\begin{tabular}{|c|c|}
\hline $\begin{array}{l}\text { D1P38 - Os profissionais da Assistência } \\
\text { Farmacêutica são convidados a participar no } \\
\text { planejamento de ações nos diferentes pontos de } \\
\text { atenção no município? }\end{array}$ & $\begin{array}{l}\text { ( ) Sim, participa ativamente } \\
\text { ( ) Sim, mas não participa } \\
\text { ( ) Não, não é convidado } \\
\text { ( ) Não sei }\end{array}$ \\
\hline $\begin{array}{l}\text { D1P47 - Os funcionários da Assistência } \\
\text { Farmacêutica se reúnem com a equipe } \\
\text { multiprofissional para discutir processos de trabalho? }\end{array}$ & 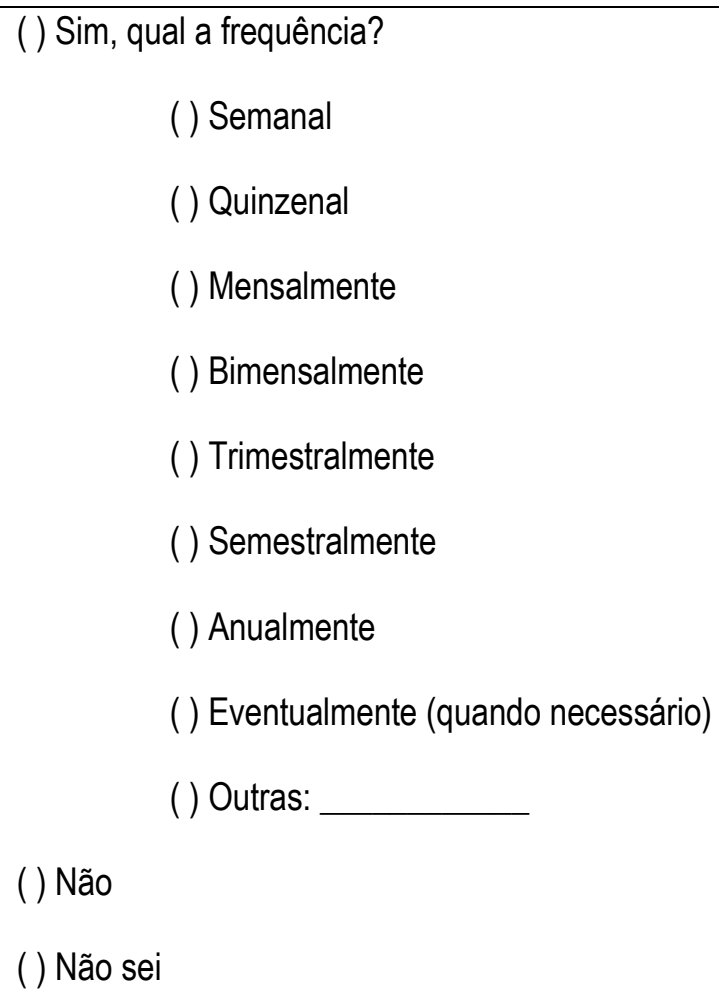 \\
\hline $\begin{array}{l}\text { D1P15 - Existe Comissão de Farmácia e Terapêutica } \\
\text { (CFT) formalmente constituída na Secretaria } \\
\text { Municipal de Saúde? } \\
\text { Resposta "Não" ou "Está em fase de implantação" ou } \\
\text { "Não sei", bloquear a D1P16 e D1P17. }\end{array}$ & $\begin{array}{l}\text { ( ) Sim } \\
\text { ( ) Não } \\
\text { ( ) Está em fase de implantação } \\
\text { ( ) Não sei }\end{array}$ \\
\hline $\begin{array}{l}\text { D1P16 - A Comissão de Farmácia e Terapêutica } \\
\text { (CFT) é composta por: }\end{array}$ & $\begin{array}{l}\text { ( ) Farmacêutico. Quantidade: } \\
\text { (drop menu de 1 a 10) } \\
\text { ( ) Enfermeiro. Quantidade: } \\
\text { (drop menu de } 1 \text { a 10) } \\
\text { ( ) Médico. Quantidade: } \\
\text { (drop menu de } 1 \text { a 10) } \\
\text { ( ) Dentista. Quantidade: }\end{array}$ \\
\hline
\end{tabular}


(drop menu de 1 a 10)

( ) Outros

( ) Não sei

( ) Não se aplica

( ) Sim. Quantas vezes

D1P17 - A Comissão de Farmácia e Terapêutica

( ) Não

(CFT) se reuniu no último ano?

( ) Não sei

( ) Não se aplica

( ) Sim, REMUME

D1P18 - Existe uma Relação Municipal de Medicamentos Essenciais (REMUME) ou uma

( ) Sim, RESME

Relação Estadual de Medicamentos Essenciais (RESME) instituída?

( ) Não

( ) Não sei

D1P20 - Há uma Relação Estadual de Medicamentos

Básicos pactuada na Comissão Intergestores () Não

Tripartite (CIB)?

( ) Não sei

( ) Dados do Município (epidemiológico)

( ) Dados do Município (consumo histórico)

( ) Evidências científicas

( ) Demanda dos serviços municipais de saúde

( ) Medicamentos de demanda judicial

D1P21 - Qual(is) o(s) critério(s) utilizado(s) para a composição da lista padronizada de medicamentos do Município?

( ) Lançamento de novos medicamentos no mercado

( ) Relatórios de controle de estoque das Unidades de Saúde

( ) Utilização da lista do Estado ou da União

( ) Adequação aos protocolos clínicos

( ) Manutenção das listas anteriores do Município

( ) Não utiliza método algum 
( ) Não existe uma lista padronizada de medicamentos

( ) Outro. Qual?

( ) Não sei

( ) Sim. Quantos itens?

D1P19 - A lista de medicamentos padronizados possui algum medicamento que não está na Relação ( ) Não

Nacional de Medicamentos Essenciais (RENAME)?

( ) Não sei

D2P18 - Há um formulário disponível para a

( ) $\operatorname{Sim}$

solicitação de inclusão/exclusão de medicamentos () Não

na lista padronizada do Município?

( ) Não sei

( ) Sim

D1P26 - Há medicamentos fitoterápicos ofertados

Manipulado

pelo município na rede pública de saúde? Resposta

"Não" ou "Não sei", bloquear D1P51, D2P48 e

D2P49

( ) Industrializado

( ) Planta Medicinal Fresca

( ) Planta Medicinal Seca (droga vegetal)

( ) Não

( ) Não sei

( ) Alcachofra (Cynara scolymus)

( ) Aroeira (Schinus terebinthifolius)

( ) Babosa (Aloe vera (L.) Burm. f.)

( ) Cáscara-sagrada (Rhamnus purshiana)

( ) Espinheira-santa (Maytenus officinalis Mabb.)

D1P51 - Quais fitoterápicos são ofertados?

( ) Garra-do-diabo (Harpagophytum procumbens)

( ) Guaco (Mikania glomerata)

( ) Hortelã (Mentha x piperita L.)

( ) Isoflavona-de-soja (Glycine max)

( ) Plantago (Plantago ovata Forssk.)

( ) Unha-de-gato (Uncaria tomentosa) 


\begin{tabular}{|c|c|}
\hline & $\begin{array}{l}\text { ( ) Salgueiro (Salix alba) } \\
\text { ( ) Outros } \\
\text { ( ) Não sei } \\
\text { ( ) Não se aplica }\end{array}$ \\
\hline $\begin{array}{l}\text { D1P27 - Há medicamentos homeopáticos ofertados } \\
\text { pelo município na rede pública? }\end{array}$ & $\begin{array}{l}\text { () Sim, contemplados na Relação Nacional de Medicamentos } \\
\text { Essenciais (RENAME) em vigência } \\
\text { ( ) Sim, outros } \\
\text { ( ) Não } \\
\text { ( ) Não sei }\end{array}$ \\
\hline $\begin{array}{l}\text { D2P48 - Em que tipo de estabelecimento são } \\
\text { entregues os fitoterápicos aos usuários? }\end{array}$ & $\begin{array}{l}\text { ( ) Farmácia pública de manipulação } \\
\text { ( ) Farmácia de dispensação unidades de saúde } \\
\text { ( ) Farmácia viva } \\
\text { ( ) Outros: } \\
\text { ( ) Não sei }\end{array}$ \\
\hline $\begin{array}{l}\text { D2P49 - Em que tipo de estabelecimento são } \\
\text { manipulados os fitoterápicos? }\end{array}$ & $\begin{array}{l}\text { ( ) Farmácia pública de manipulação } \\
\text { ( ) Farmácia de manipulação conveniada } \\
\text { ( ) Farmácia viva } \\
\text { ( ) Outros: } \\
\text { ( ) Não sei } \\
\text { ( ) Não se aplica. }\end{array}$ \\
\hline $\begin{array}{l}\text { D3P21 - A equipe de Saúde realiza atividades de } \\
\text { educação em saúde que aborde o uso de plantas } \\
\text { medicinais e/ou fitoterápicos? Resposta "Não" ou } \\
\text { "Não sei", bloquear D3P22 }\end{array}$ & $\begin{array}{l}\text { ( ) Sim } \\
\text { ( ) Não } \\
\text { ( ) Não sei }\end{array}$ \\
\hline $\begin{array}{l}\text { D3P22 - Quem realiza atividades de educação em } \\
\text { saúde abordando o uso de plantas medicinais e/ou } \\
\text { fitoterápicos? }\end{array}$ & $\begin{array}{l}\text { ( ) Farmacêuticos } \\
\text { ( ) Médicos } \\
\text { ( ) Enfermeiro } \\
\text { ( ) Técnico/Auxiliar de Farmácia }\end{array}$ \\
\hline
\end{tabular}




\begin{tabular}{|c|c|}
\hline & $\begin{array}{l}\text { ( ) Técnico/Auxiliar de Enfermagem } \\
\text { ( ) Agente Comunitário de Saúde } \\
\text { ( ) Outros: } \\
\text { ( ) Não sei }\end{array}$ \\
\hline $\begin{array}{l}\text { D3P17 - No município existe farmácia de } \\
\text { dispensação de medicamentos do componente } \\
\text { especializado da Assistência Farmacêutica? }\end{array}$ & $\begin{array}{l}\text { ( ) Sim } \\
\text { ( ) Não. Qual o local de referência para o Município: } \\
\text { ( ) Não sei }\end{array}$ \\
\hline $\begin{array}{l}\text { D3P19 - É informado ao usuário de como ter acesso } \\
\text { aos medicamentos do componente especializado? } \\
\text { Resposta "Não" ou "Não sei", bloquear a D3P20. }\end{array}$ & 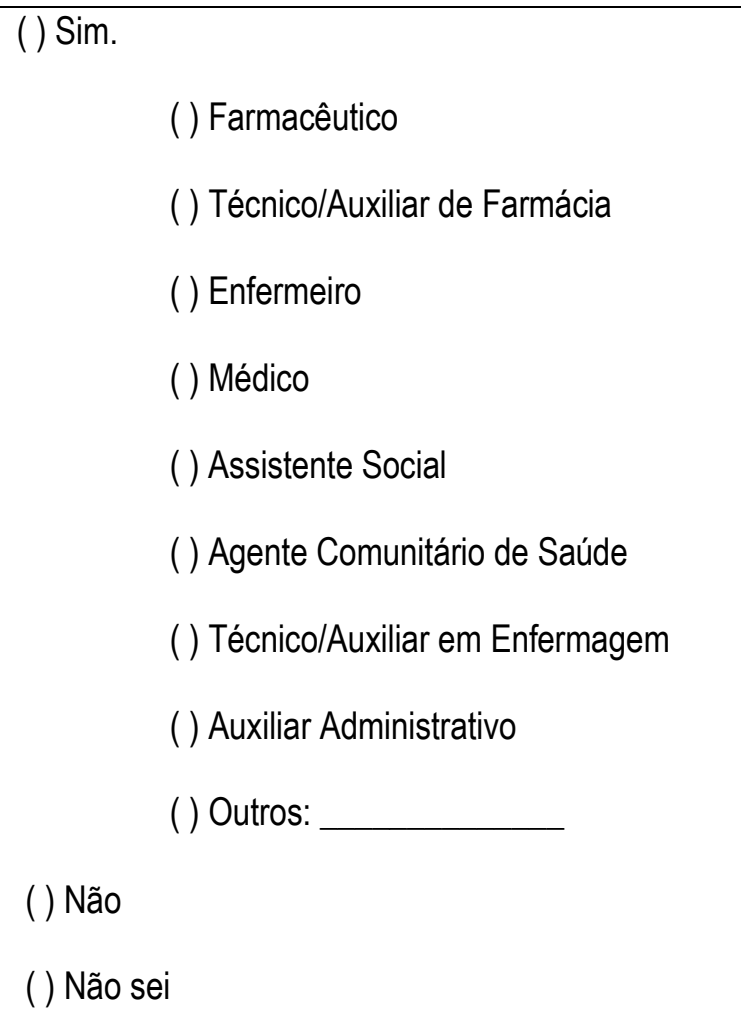 \\
\hline $\begin{array}{l}\text { D3P20 - Como o usuário é informado sobre acesso } \\
\text { aos medicamentos do componente especializado da } \\
\text { Assistência Farmacêutica? }\end{array}$ & $\begin{array}{l}\text { ( ) Verbalmente } \\
\text { () Panfleto } \\
\text { ( ) Cartaz } \\
\text { () Protocolo clínico impresso } \\
\text { () Internet } \\
\text { () Outros } \\
\text { ( ) Não sei }\end{array}$ \\
\hline D1P11 - Existe elaboração de informativos pela & ( ) S \\
\hline
\end{tabular}




\begin{tabular}{|c|c|}
\hline $\begin{array}{l}\text { equipe da Assistência Farmacêutica do Município } \\
\text { para o usuário? }\end{array}$ & $\begin{array}{l}\text { ( ) Não } \\
\text { ( ) Não sei }\end{array}$ \\
\hline $\begin{array}{l}\text { D1P13 - Há disponibilidade de Informação visível ao } \\
\text { usuário sobre os locais de dispensação de } \\
\text { medicamentos padronizados? }\end{array}$ & $\begin{array}{l}\text { ( ) Sim. Qual a forma? } \\
\text { (na página eletrônica do Município, cartaz, panfleto ou outras } \\
\text { formas) } \\
\text { ( ) Não } \\
\text { ( ) Não sei }\end{array}$ \\
\hline $\begin{array}{l}\text { D1P14 - O Município disponibiliza a lista de } \\
\text { medicamentos padronizados (e suas atualizações) } \\
\text { impressa nos consultórios dos prescritores? }\end{array}$ & $\begin{array}{l}\text { ( ) Sim } \\
\text { ( ) Não } \\
\text { ( ) Não sei }\end{array}$ \\
\hline $\begin{array}{l}\text { D1P33 - Existe um sistema informatizado* para a } \\
\text { gestão da Assistência Farmacêutica? } \\
\text { *Sistema informatizado entende-se por software e } \\
\text { não apenas uma planilha do Microsoft Excel. } \\
\text { Resposta "Não" ou "Não sei", bloquear D2P16, } \\
\text { D1P34, D1P35 e D1P36. }\end{array}$ & $\begin{array}{l}\text { ( ) Sim, Hórus } \\
\text { ( ) Sim, sistema informatizado próprio, desenvolvido pelo } \\
\text { município } \\
\text { ( ) Sim, sistema informatizado terceirizado } \\
\text { ( ) Sim Outro? } \\
\text { ( ) Não } \\
\text { ( ) Não sei }\end{array}$ \\
\hline $\begin{array}{l}\text { D2P16 - Existe no estabelecimento/município um } \\
\text { sistema informatizado atende as exigências da } \\
\text { Portaria GM/MS n. } 271 \text {, de } 27 \text { de fevereiro de } 2013 ?\end{array}$ & $\begin{array}{l}\text { ( ) Sim } \\
\text { ( ) Não } \\
\text { ( ) Não sei }\end{array}$ \\
\hline $\begin{array}{l}\text { D1P34 - Quais funcionalidades são disponibilizadas } \\
\text { pelo sistema informatizado? }\end{array}$ & $\begin{array}{l}\text { ( ) Aquisição } \\
\text { ( ) Dispensação } \\
\text { ( ) Controle de estoque } \\
\text { ( ) Armazenamento } \\
\text { ( ) Distribuição } \\
\text { ( ) Relatórios } \\
\text { ( ) Informação de medicamentos (validade, lote, informações } \\
\text { farmacológicas etc.) }\end{array}$ \\
\hline
\end{tabular}




\begin{tabular}{|c|c|}
\hline & $\begin{array}{l}\text { ( ) Não sei } \\
\text { ( ) Não se aplica }\end{array}$ \\
\hline $\begin{array}{l}\text { D1P35 - Quais funcionalidades são utilizados pelo } \\
\text { sistema informatizado? }\end{array}$ & $\begin{array}{l}\text { ( ) Aquisição } \\
\text { ( ) Dispensação } \\
\text { ( ) Controle de estoque } \\
\text { ( ) Armazenamento } \\
\text { ( ) Distribuição } \\
\text { ( ) Relatórios } \\
\text { ( ) Informação de medicamentos (validade, lote, informações } \\
\text { farmacológicas etc.) } \\
\text { ( ) Não utiliza o sistema } \\
\text { ( ) Não sei }\end{array}$ \\
\hline $\begin{array}{l}\text { D1P36 - O sistema informatizado está em rede com } \\
\text { as Unidades de Saúde? }\end{array}$ & $\begin{array}{l}\text { ( ) Sim } \\
\text { ( ) Não } \\
\text { ( ) Não sei }\end{array}$ \\
\hline $\begin{array}{l}\mathrm{D} 1 \mathrm{P} 28 \text { - } \mathrm{Na}(\mathrm{s}) \text { unidade }(\mathrm{s}) \text { que dispensa }(\mathrm{m}) \\
\text { medicamentos, existe cronograma de envio das } \\
\text { informações para programação da aquisição de } \\
\text { medicamentos? }\end{array}$ & $\begin{array}{l}\text { ( ) Sim } \\
\text { ( ) Não } \\
\text { ( ) Não sei } \\
\text { ( ) Não se aplica }\end{array}$ \\
\hline $\begin{array}{l}\text { D1P30 - Qual o critério utilizado, no último ano, na } \\
\text { programação para aquisição de medicamentos? }\end{array}$ & $\begin{array}{l}\text { ( ) Consumo médio } \\
\text { ( ) Perfil epidemiológico } \\
\text { ( ) Oferta de serviço } \\
\text { ( ) Recurso disponível } \\
\text { ( ) Outro } \\
\text { ( ) Não sei }\end{array}$ \\
\hline $\begin{array}{l}\text { D1P29 - Existe cronograma de envio do pedido para } \\
\text { abastecimento das unidades para a Central de } \\
\text { Abastecimento Farmacêutico (CAF)? }\end{array}$ & $\begin{array}{l}\text { ( ) Sim } \\
\text { ( ) Não } \\
\text { ( ) Não sei }\end{array}$ \\
\hline
\end{tabular}




\begin{tabular}{|c|c|}
\hline & ica \\
\hline $\begin{array}{l}\text { D2P30 - Quantos itens estão faltando no momento, } \\
\text { em relação à lista padronizada? }\end{array}$ & $\begin{array}{l}N^{0} \text { de medicamentos em falta: } \\
\text { ( ) Não sei }\end{array}$ \\
\hline $\begin{array}{l}\text { D2P23 - Quando ocorre desabastecimento, qual(is) } \\
\text { o(s) motivo(s)? }\end{array}$ & $\begin{array}{l}\text { ( ) Problemas do setor de compras } \\
\text { ( ) Problemas do mercado farmacêutico } \\
\text { () Problemas de repasses de medicamentos nas instâncias do } \\
\text { SUS } \\
\text { ( ) Atraso na distribuição para as Unidades } \\
\text { () Atraso na entrega do distribuidor/fornecedor } \\
\text { ( ) Outro: } \\
\text { ( ) Não sei } \\
\text { () Não se aplica }\end{array}$ \\
\hline $\begin{array}{l}\text { D2P24 - Qual o procedimento adotado com o } \\
\text { usuário, quando falta algum medicamento? }\end{array}$ & $\begin{array}{l}\text { ( ) Encaminha o usuário para outra unidade } \\
\text { ( ) Encaminha para o Programa Farmácia Popular } \\
\text { ( ) Encaminha para uma farmácia comercial } \\
\text { ( ) Registra o contato do usuário para avisar quando o } \\
\text { medicamento chegar } \\
\text { () Solicita o retorno posteriormente } \\
\text { () Nenhum procedimento é adotado } \\
\text { () Outro }\end{array}$ \\
\hline $\begin{array}{l}\text { D2P25 - Quando há excesso de medicamentos no } \\
\text { estoque, qual o procedimento adotado? }\end{array}$ & $\begin{array}{l}\text { ( ) Ajuste na programação } \\
\text { ( ) Redistribuição entre Unidades de Saúde } \\
\text { ( ) Devolução para a Central de Abastecimento Farmacêutico } \\
\text { (CAF) } \\
\text { ( ) Doação } \\
\text { ( ) Realiza troca com outros serviços do município } \\
\text { ( ) Empréstimo dentro da rede (outros municípios/Estado) } \\
\text { ( ) Perde-se o que sobrou }\end{array}$ \\
\hline
\end{tabular}




\begin{tabular}{|c|c|}
\hline & $\begin{array}{l}\text { ( ) Não há excesso } \\
\text { ( ) Outro: } \\
\text { ( ) Não sei }\end{array}$ \\
\hline $\begin{array}{l}\text { D2P19 - Para qual(is) atividade(s) existe } \\
\text { procedimento operacional padrão (POP)? }\end{array}$ & $\begin{array}{l}\text { ( ) Recepção de medicamentos e insumos } \\
\text { ( ) Armazenamento de medicamentos e insumos } \\
\text { ( ) Dispensação de medicamentos } \\
\text { ( ) Controle de temperatura e umidade } \\
\text { ( ) Controle de estoque } \\
\text { ( ) Limpeza } \\
\text { ( ) Fluxo de abastecimento } \\
\text { ( ) Plano de gerenciamento de resíduos de serviços de saúde } \\
\text { (PGRSS) } \\
\text { ( ) Outros } \\
\text { ( ) Não possui }\end{array}$ \\
\hline $\begin{array}{l}\text { D2P20 - Existe registro diário de entrada e saída de } \\
\text { medicamentos no estabelecimento? }\end{array}$ & $\begin{array}{l}\text { ( ) Sim, Hórus } \\
\text { () Sim, sistema informatizado próprio, desenvolvido pelo } \\
\text { município } \\
\text { ( ) Sim, sistema informatizado terceirizado } \\
\text { ( ) Sim, planilha de Excel } \\
\text { () Sim, ficha de prateleira } \\
\text { () Sim, manual } \\
\text { ( ) Sim. Outro? } \\
\text { () Não } \\
\text { () Não sei }\end{array}$ \\
\hline $\begin{array}{l}\text { D2P21 - O inventário (balanço) dos medicamentos } \\
\text { sujeitos a controle especial armazenados no(s) } \\
\text { estabelecimento(s) é feito: }\end{array}$ & $\begin{array}{l}\text { ( ) Semanalmente } \\
\text { ( ) Quinzenalmente } \\
\text { ( ) Mensalmente } \\
\text { ( ) Trimestralmente }\end{array}$ \\
\hline
\end{tabular}




\begin{tabular}{|c|c|}
\hline & $\begin{array}{l}\text { ( ) Semestralmente } \\
\text { ( ) Anualmente } \\
\text { ( ) Não é feito } \\
\text { ( ) Não há medicamentos sujeitos a controle especial }\end{array}$ \\
\hline $\begin{array}{l}\text { D2P21.1 - O inventário (balanço) dos medicamentos } \\
\text { armazenados no(s) estabelecimento(s) é feito: }\end{array}$ & $\begin{array}{l}\text { ( ) Semanalmente } \\
\text { ( ) Quinzenalmente } \\
\text { ( ) Mensalmente } \\
\text { ( ) Trimestralmente } \\
\text { ( ) Semestralmente } \\
\text { ( ) Anualmente } \\
\text { ( ) Não é feito } \\
\text { ( ) Possui apenas medicamentos sujeitos a controle especial }\end{array}$ \\
\hline $\begin{array}{l}\text { D2P26 - Existe um plano de gerenciamento de } \\
\text { resíduos de serviços de saúde (PGRSS), no } \\
\text { município? }\end{array}$ & $\begin{array}{l}\text { ( ) Sim } \\
\text { ( ) Não } \\
\text { ( ) Não sei }\end{array}$ \\
\hline $\begin{array}{l}\text { D2P28 - Existe um serviço de recolhimento de } \\
\text { resíduos de medicamentos (embalagens, sobras, } \\
\text { medicamentos inapropriados para o consumo) do } \\
\text { estabelecimento? }\end{array}$ & $\begin{array}{l}\text { ( ) Sim } \\
\text { ( ) Não } \\
\text { ( ) Não sei }\end{array}$ \\
\hline $\begin{array}{l}\text { D3P23 - É realizado agendamento* da dispensação } \\
\text { de medicamentos de uso contínuo (tratamento de } \\
\text { condições crônicas) em algum estabelecimento? }\end{array}$ & 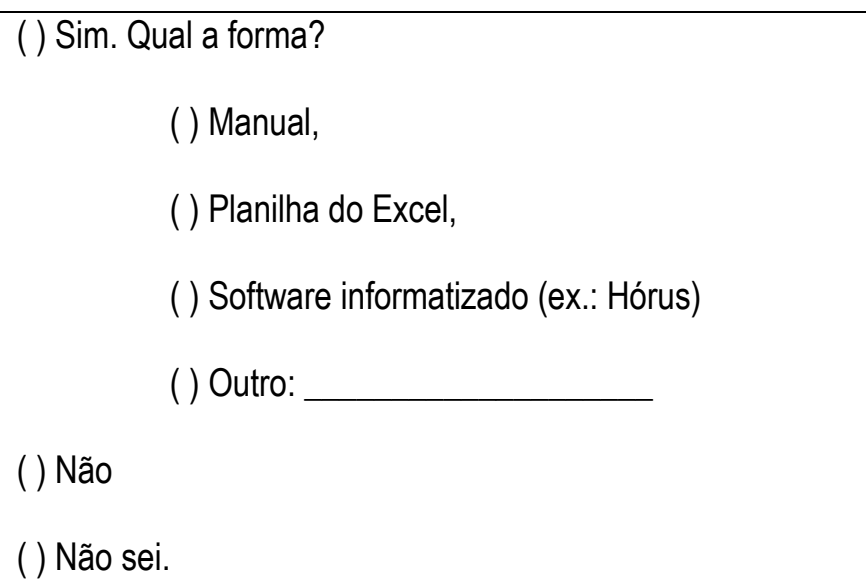 \\
\hline $\begin{array}{l}\text { D3P24 - Qual procedimento adotado quando é } \\
\text { identificado o NÃO comparecimento do usuário na }\end{array}$ & ( ) Busca ativa pela equipe da Assistência Farmacêutica \\
\hline
\end{tabular}


retirada de medicamentos?

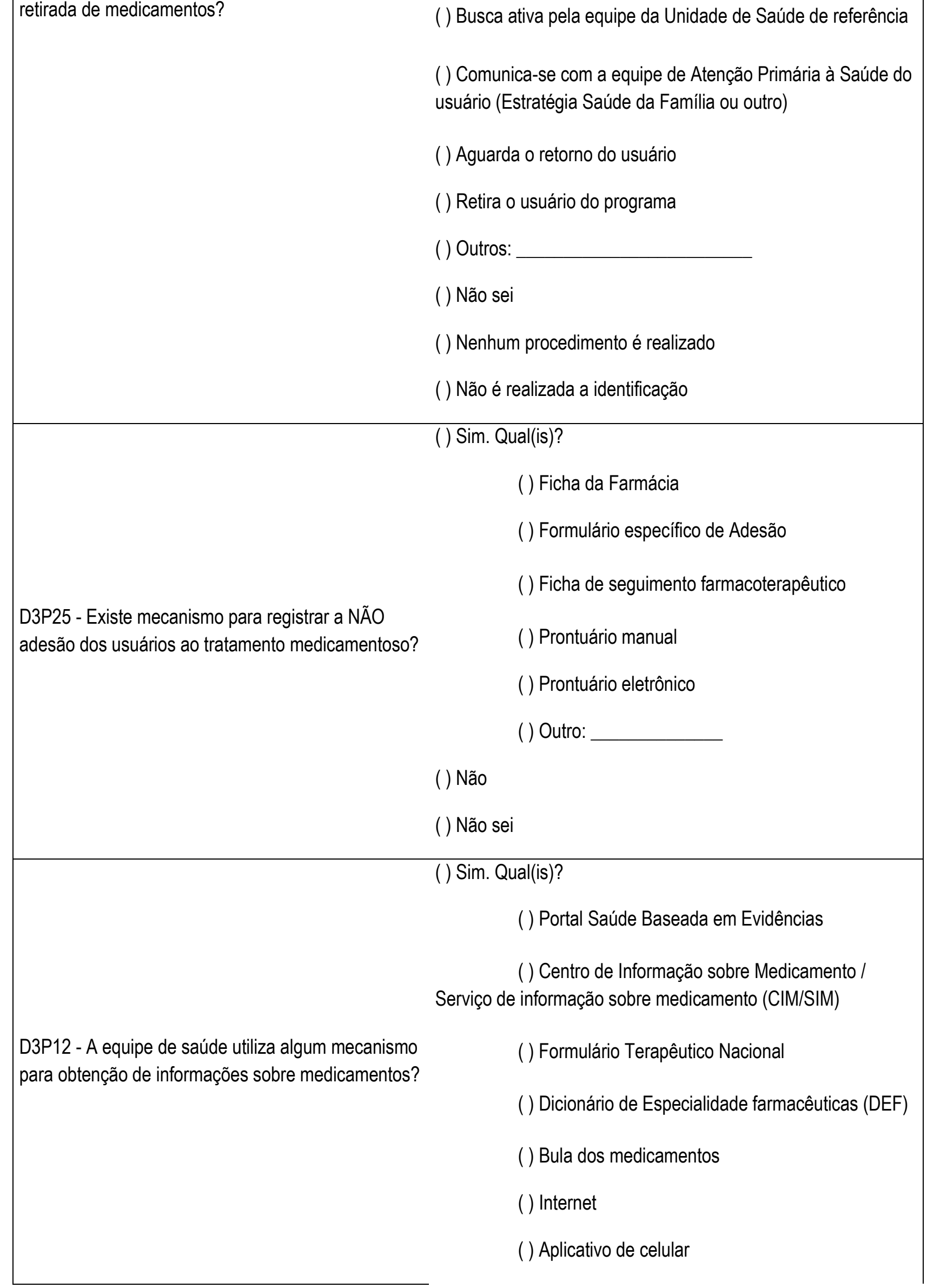


( ) Outros:

( ) Não

( ) Não sei

( ) Sim, na farmácia

( ) Sim, no consultório do prescritor

D2P38 - Existem amostras grátis no estabelecimento sendo entregue ao usuário neste estabelecimento?

( ) Sim, outro local:
( ) Não
( ) Não sei

D2P39 - No(s) estabelecimento(s) recebe visita de representante/propagandista da

( ) Sim

indústria/distribuidora de medicamentos?

( ) Não

( ) Não sei

D3P03 - É realizada a notificação de queixas e/ou

( ) Sim

eventos adversos a medicamentos? Resposta "Não"

( ) Não

ou "Não sei", bloquear D3P08 e D3P09

( ) Não sei

D3P07 - Existe fluxo/procedimento para a notificação

\section{() Sim}

de queixa e/ou evento adverso de medicamento no

Município?

( ) Não

( ) Não sei

( ) Nenhum

( ) Encaminhado para o nível central da Assistência

Farmacêutica

( ) Sistema de notificações em vigilância sanitária - NOTIVISA

( ) Encaminhado para Vigilância em Saúde municipal;

D3P08 - Qual é o encaminhamento dado às queixas técnicas e/ou eventos adversos a medicamentos?

( ) Encaminhado para outro setor. Qual?

( ) Encaminhado para outro profissional. Qual?

( ) Não recebemos notificações de efeitos adversos

() Outros encaminhamentos

( ) Não sei 
D3P09 - No último ano, qual o número de queixa e/ou notificações de eventos adversos relacionado a medicamentos foram registrados?

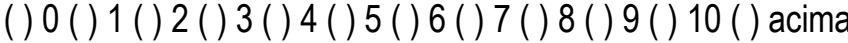
de 10:

( ) Não sei

( ) Nenhuma
D3P10 - Qual(is) procedimento(s) adotado(s) quando há publicação de alertas técnicos sobre medicamentos que não estão em conformidade com a Agência Nacional de Vigilância Sanitária (ANVISA)?
( ) Divulgação do alerta para os estabelecimentos;

( ) Divulgação para os profissionais de saúde;

( ) Divulgação da informações na mídia local.

() Recolhimento do produto

() Outros:

( ) Não realiza nenhuma ação.

( ) Sim, por programa formalizado para a entrega de medicamentos em casa, no Município

D2P40 - Há serviço de entrega de medicamentos em casa?

Resposta "Não" ou "Não sei", bloquear D2P41,

D2P42, D2P43, D3P62, D2P44, D2P45, D2P47.

( ) Sim, por programa não formalizado no Município

( ) Não

( ) Não sei

( ) Idosos sem cuidadores/ responsáveis/dificuldade de locomoção

( ) Usuários de Cuidados paliativos

D2P41 -Qual(is) o(s) usuário(s) atendido(s) neste

( ) Usuários de medicamentos de uso contínuo serviço?

( ) Residentes em locais de difícil acesso

( ) Usuários do serviço de Saúde Mental

( ) Usuário com deficiência

( ) Outros:

( ) Não sei

( ) Medicamentos do Componente Básico da Assistência Farmacêutica

D2P42 - Quais são os medicamentos entregues?

( ) Medicamentos do Componente Especializado da Assistência 


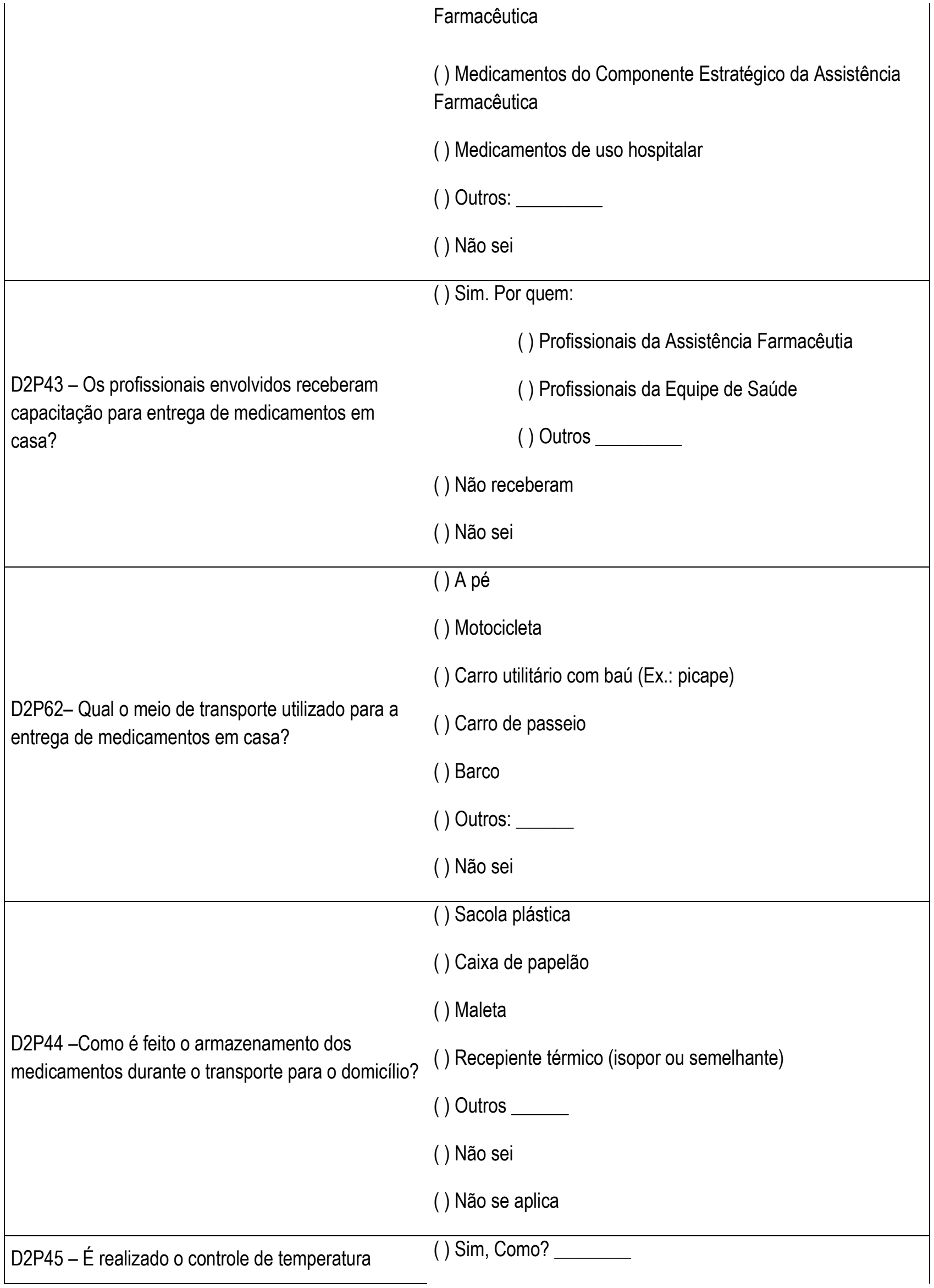




\begin{tabular}{|ll} 
durante o transporte para o domicílio? & ( ) Não realiza \\
& ( ) Não sei \\
& ( ) Não se aplica \\
& ( ) Profissionais do Núcleo de Apoio à Saúde da Família \\
& (NASF) \\
& ( ) Visita Domiciliar pela Equipe de Saúde da Família (ESF) \\
& ( ) Profissionais das Unidades de Saúde/Centro de Atenção \\
& Psicossocial (CAPS) \\
D2P47 - Quem faz o acompanhamento destes & ( ) Programa Melhor em Casa \\
usuários? & ( ) Programa Assistência Domiciliar (PAD) \\
& () Outros \\
& () Não realiza \\
( ) Não sei
\end{tabular}


COMPROVANTE DE SUBMISSÃO DO ARTIGO

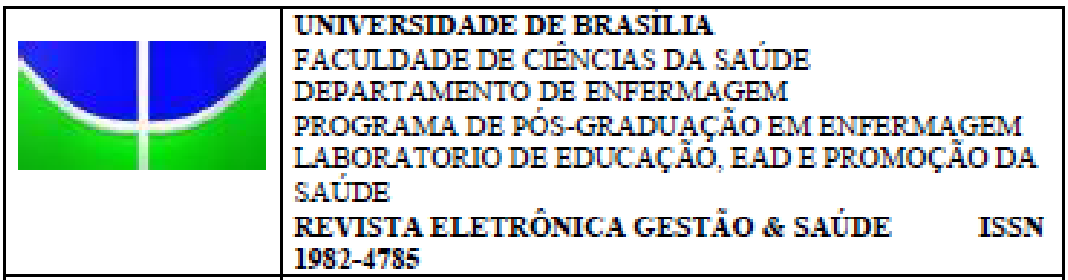

Brasilia, 27 de dezembro de 2016

Ao Senhor Wendell Oliveira

Ref.: Comprovante de submissão

Informamos que o artigo "GESTÃo DA ASSISTÊNCIA FARMACÊUTICA EM REGIÕES DE SAÚDE DO CEARÁ: um recorte do Projeto QualiSUS-Rede" de sua autoria e de Karen Sarmento Costa, Noemia Unuth Leão Tavares foi submetido na revista Gestão \& Saúde.

Obrigada pelo apoio e parceria

Cordialmente,

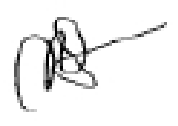
Andrea de Oliveira Gonçalves
Professora adjunta
Universidade de Brasilia
Matricula 1027387

Editora Chefe 